\title{
Metabolic control of embryonic dormancy in apple seed: seven decades of research
}

\author{
Stanisław Lewak
}

Received: 17 December 2009/Revised: 12 April 2010/Accepted: 10 May 2010/Published online: 30 May 2010

(C) The Author(s) 2010. This article is published with open access at Springerlink.com

\begin{abstract}
Embryonic dormancy is defined as a set of blocks imposed upon a process(es) cardinal for growth. In apple seeds, all these blocks are removed as a result of cold treatment (stratification), but some of them are also affected by light and/or hormonal treatments. This review summarizes published data related to the modes of action of above factors on the changes in the levels of endogenous hormones and some other plant growth regulators (e.g., hydrogen cyanide), and on certain enzymes involved in mobilization of seed reserves and catabolism of their hydrolysis products. Phytochrome and activities of acid lipase and a protease have been indicated as receptors of light and low temperature, respectively. Several chains of events initiated by these two environmental factors and leading to dormancy removal are proposed, and the sites of their control by hormones and HCN are indicated. These chains are postulated to contribute to the elimination of particular blocks that hinder germination and therefore to be involved in the mechanisms of dormancy breakage.
\end{abstract}

Keywords Abscisic acid - Cytokinins - Ethylene . Germination · Gibberellins · Hydrogen cyanide . Imbibition - Invertases - Jasmonic acid - Isocitrate lyase . Lipases · Photosynthetic enzymes · Proteases · Pyruvate kinase $\cdot$ Stratification

Communicated by A. Kononowicz.

S. Lewak $(\square)$

Institute of Plant Experimental Biology, Warsaw University,

Miecznikowa 1, 02-096 Warsaw, Poland

e-mail:slewak@biol.uw.edu.pl

S. Lewak

Institute of Biochemistry and Biophysics, Polish Academy

of Sciences, Pawińskiego 5a, 02-106 Warsaw, Poland

\section{Introduction}

Dormancy and processes cardinal for growth

Dormancy in plants, wherever it is observed, can be defined as a temporal cessation of growth of a plant meristem. All the classifications of dormancy are related to the organ and/or tissue where the inhibition of growth takes place, to the kind of factor that affects dormancy and, more recently, to the relationship between the site of action of this factor and the location of inhibited (dormant) meristem (Lang 1987).

For a normal, harmonious growth of a plant, a set of individual, coordinated processes have to occur in order to supply the growing cells with metabolic energy and materials for syntheses of cell components, as well as to maintain, modify, and build new structures. The supply of energy and materials ought to take place at the right time, in optimal amounts, and in the right place. These processes are not identical in different meristems; their occurrence (activity) may be limited to some organs, species, and physiological situations, but provided that they are indispensable for normal growth-they are implicated in the control of growth, and therefore, are considered to be the cardinal processes for growth. To the best of my knowledge, the concept of cardinal processes for physiological phenomena in plants (also called "essential processes") was developed by Daphne Osborne in early 1980s (Osborne 1981; Osborne et al. 1984), but it had already been exploited earlier (e.g., processes cardinal for seed formation; Pate 1975).

The concept of cardinal processes allows for a definition of dormancy that follows the definition mentioned above. According to this definition, which will be used throughout this paper, dormancy is a block, or a set of blocks, imposed 
upon a process(es) cardinal for growth. The induction and breakage of dormancy results from modifications in the control of cardinal processes associated with growth. Elimination of all blocks leads to the restoration of normal growth, and thus, it is equivalent to complete removal of dormancy.

Reversible inhibition of meristematic growth occurs during all stages of plant ontogenesis and may concern almost all organs and tissues. Some of these events are not commonly considered as dormancy (e.g., temporal growth cessation due to stress conditions, correlative inhibitions, etc.). Moreover, dormancy is often observed only under certain environmental conditions, and therefore, it is considered as a relative phenomenon (e.g., Côme 1980/81). Nevertheless, accepting the above description of dormancy, it seems reasonable to use one term for all the phenomena based on the same fundamental mechanism, as it was done by Lang (1987) who has proposed an universal dormancy terminology. Obviously, the character of the inhibited process, the kind of block, the mode of its onset and elimination, and the factors involved contribute to the determination of the type (class) of dormancy.

\section{Germination and dormancy in seeds}

Although the mechanisms of growth inhibition in different dormant organs and tissues have been extensively studied (for a review see, e.g., Kozlowski and Pallardy 2002), investigations in which dormant seeds were used as a model material are the most abundant and yielded the most interesting results. In contrast to the majority of other phases in plant ontogenesis, germination of seeds is characterized by the absence of cellular growth and differentiation. By definition, germination incorporates those events that commence with the uptake of water by the quiescent dry seed and terminate with the elongation of the embryonic axis (Bewley 1997). The beginning of growth, manifested by protrusion of the radicle through the seed coat, denotes the end of germination and the beginning of the next developmental phase-the vegetative growth. The above definition of germination corresponds to the term "early germination" or "germination sensu stricto" used by some authors.

The initiation of growth is critically dependent on the processes cardinal for seed germination, defined as above. Some of them are identical with the cardinal processes for the preceding and/or following developmental phases (embryogenesis and early growth, respectively). Some other processes cardinal for germination also occur during other developmental phases, but are not cardinal for those phases. Finally, some processes cardinal for germination are unique to this phase. Table 1 shows examples of processes cardinal for germination.
Table 1 Examples of processes cardinal for germination

Hydration of cell colloids and related conformational changes in macromolecules

Activation of membrane repair systems

Activation of energy generating systems

Activation of DNA repair systems

Expression of specific genes, synthesis of "germination proteins" (e.g., $\alpha$-amylase, isocitrate lyase, and malate synthase)

Activation of some enzymes (e.g., $\beta$-amylase, lipases, and glycolytic enzymes)

Mobilization of reserves (carbohydrates, lipids, and proteins)

Metabolism of reserves (e.g., glyoxylate cycle and gluconeogenesis)

Activation of hormone metabolism (synthesis and reversible conjugation)

Activation of intercellular and inter-organ translocations

Undisturbed course of all cardinal processes leads to the end of germination and hence to normal growth of a seedling. Any obstacle, inhibition, or barrier affecting these processes is involved in the onset and maintenance of dormancy.

Usually, more than one mechanism is implicated in the dormancy in seeds, i.e., more than one process cardinal for germination is inhibited or slowed down. This complex nature of dormancy is one of the causes of the different depth (intensity) of dormancy in different seeds. In another words, many different intermediate physiological states exist between a non-dormant and a deeply dormant seed, resulting in differences in germination and important developmental anomalies (Côme 1980/81; Bouyon and Bulard 1986). Moreover, any lot of seeds of a given species (cultivar) is always heterogeneous as far the depth of their dormancy is concerned. Each seed in a batch may be in a slightly different physiological state. It depends on such factors as the climatic conditions of fruit ripening, fruit localization on the tree, the number of seeds in the fruit, localization of the seeds in the carpellar cavity, seed storage conditions, etc. The dormancy of seeds in a batch is characterized by its germination rate, by the eventual percentage of germinated seeds, and by the degree and frequency of seedling anomaly. All these parameters have a statistical character and describe the physiological state of a population, but not of an individual seed.

Although the primary mechanisms of dormancy evidently rely upon the heritable genetic features, one of the most frequently postulated (and studied) mechanisms for control of seed dormancy is a block in reserve mobilization (e.g., Villiers 1972; Lewak 1981; Drewes and Van Staden 1991; Foley et al. 1993). Nevertheless, several reservations related to that opinion have been put forward (Bewley 1997). They are based on the fact that the processes 
cardinal for the release of seeds from dormancy and the completion of germination may occur only within the relatively few cells of the embryonic root axis. Therefore, only subtle differences in the cellular and metabolic events between imbibed dormant and non-dormant seeds are frequently observed. This methodological problem was noticed earlier by Côme (1980/81).

Apple seeds as a model material

The metabolic events that occur during the onset, maintenance, and removal of deep embryonic dormancy in seeds have been studied using different experimental models. For starchy mono-cotyledons, the seeds of barley and wild oat were most frequently studied (for example Dyer 1993; Wang et al. 1995; Han et al. 1996). For the studies of the dormancy control in oily annuals, lettuce achenes (e.g., Fountain and Bewley 1973; Hsiao and Vidaver 1989) and sunflower seeds (e.g., Srivastava and Dey 1982; Gay et al. 1991) were used, whereas apple seeds, in parallel to hazel (e.g., Jarvis et al. 1968) and Acer (e.g., Pinfield and Dungey 1985), seem to be the most extensively investigated model material for studies of dormancy in oily perennial dicotyledonous seeds. The obvious reason of the interest in such a material is the economic value of apples, but also the fact that apple seed dormancy is so well expressed; besides, the embryonic dormancy, which is completely removed by chilling only (cryogenic endodormancy, according to Lang 1987), there is also another kind of dormancy: the coatimposed inhibition (testa paradormancy). Moreover, apple seeds are easily available, convenient to handle in largescale experiments, and their manipulation to isolate embryos and their parts is fairly straightforward. For these reasons, apple seeds have been utilized for decades for studies of different aspects of dormancy in different research centers all over the world in the temperate zones.

The first thorough description of dormancy in seeds apple come from the Boyce Thompson Institution (Flemion 1934). The absolute requirement of cold treatment for normal germination and growth of seedlings, as well as the testa-independent dormancy of embryo, were then demonstrated. Three decades later, this research was supplemented in France by Côme (1970, 1980/81). He described precisely the physiological and morphological aspects of embryo dormancy and its consequences for seedling development. He also demonstrated the role of cotyledons as well as the involvement of respiratory processes in the maintenance and removal of embryonic dormancy. In parallel, studies on plant growth regulators responsible for apple seed dormancy were initiated in Great Britain (Luckwill et al. 1969), France (Nitsch 1958; Isaia and Bulard 1978), USSR (Nikolaeva and Jankelevitch 1976), and Poland (Rudnicki 1969; Sińska and Lewak 1970).
Investigation of the metabolic events that occur in these seeds during dormancy removal and germination was undertaken in the late 1960s in our laboratory (e.g., Lewak et al. 1975).

Several different experimental approaches have been used during studies of dormancy in apple seeds, and not always the same cultivar of apple was used in different laboratories. As a rule, some physiological features, levels of different metabolites, and growth regulators as well as some enzyme activities in dormant seeds were compared with those in completely or partly non-dormant ones. The standard procedure of dormancy removal is a treatment of imbibed intact seeds with low positive temperature for different periods (stratification), which lasts up to 3 months depending on apple cultivar. The cold treatment of isolated seeds can be substituted by the chilling of seeds within the fruit (cold storage of apples; Harrington and Hite 1923; Côme 1970). Both treatments affect all types (kinds) of apple seed dormancy (embryonic and testa-imposed). Isolated embryos show only the deep embryonic dormancy (obviously no coat-imposed one), and when cultured under different temperature and light conditions for different periods, their dormancy is gradually eliminated. It is of some interest that apple embryo dormancy can be eliminated at room temperature by an anaerobic treatment lasting several days (Tissaoui and Côme 1973). Isolated embryos in culture can be additionally submitted to treatments with different factors (e.g., chemicals). Such an approach may be a source of valuable information that cannot be obtained using intact seeds for experimentation.

\section{Environmental factors that affect dormancy in apple seeds}

\section{Water}

Apple seeds kept inside fruits at the harvest contain ca. $45 \%$ of water relative to the dry weight (d.w.). During drying of seeds, the water content decreases to ca. $10 \%$ d.w., but in seeds submitted to stratification or in isolated embryos in culture it can reach $250 \%$ of d.w. (Thévenot and Côme 1971; Thévenot 1980). Interestingly, the water content in cotyledons does not change markedly during seed stratification, whereas in embryo axes it may increase up to sevenfold following moist cold treatment (Eichholtz et al. 1983).

The dormancy in mature seeds extracted from apples after harvest is not definitively established. It increases upon seed drying and during the first weeks of dry storage. Hydration of the embryo is an essential condition that allows dormancy removal; no factor affecting dormancy is efficient without at least partial hydration of the embryo. 
The lower hydration (more negative water potential) in seeds inside the fruit is one of the reasons of the longer chilling period required for complete removal of dormancy, in comparison to seeds imbibed under conditions of unlimited water supply.

\section{Temperature}

The depth (degree) of seed dormancy is usually expressed as the shortest time period of cold treatment of imbibed seeds sufficient to allow their germination. The germination is scored either at the temperature of stratification (chilling) or at a higher temperature optimal for germination.

Dry seeds do not lose their viability after extreme temperature treatments. In contrast, the frost $\left(-7^{\circ} \mathrm{C}\right)$ resistance of hydrated seeds decreases when they are kept inside fruits at $0^{\circ} \mathrm{C}$, the temperature that eliminates embryonic dormancy (Nguyen and Côme 1984).

As it has been already noted ("Apple seeds as a model material"), embryonic dormancy in hydrated apple seeds is completely eliminated by a low temperature treatment. The progress of the release from dormancy under these conditions, expressed as an increase in germinability of isolated embryos, is presented in Fig. 3. Taking into account the dynamics of the increase, three successive phases can be distinguished. Côme (1980/81) has demonstrated that there are different thermal optima for processes related to successive phases of germination sensu lato: dormancy breakage, germination sensu stricto, and the post-germinative events (growth of the radicle). The lowest temperature, with an optimum at $5^{\circ} \mathrm{C}$, is required for the breaking of dormancy, but the successive processes (germination sensu stricto and growth) can proceed only slowly under these conditions. The optimum for germination is $18^{\circ} \mathrm{C}$, and it can take place in temperatures up to $30^{\circ} \mathrm{C}$. The optimum temperature for the growth of germinated radicle is around $30^{\circ} \mathrm{C}$. These observations are not in full agreement with the idea of Vegis (1964) who suggested that the broadening of the temperature range for germination resulting from extended cold treatment is a general characteristic of cold-requiring seeds. Nevertheless, the fact that the temperature ranges in which the processes belonging to different phases of germination sensu lato overlap, as it is shown in Fig. 1, explains why a dormant apple seed kept for a sufficient time at $5^{\circ} \mathrm{C}$ finally germinates and produces a healthy seedling, but is unable to germinate when kept at $30^{\circ} \mathrm{C}$. Moreover, a partly or completely non-dormant imbibed seed kept for a time as short as 3 days at 25 or $30^{\circ} \mathrm{C}$ enters secondary dormancy and does not germinate even under favorable temperature conditions (Kamiński and Zagaja 1974; Bulard 1986). The secondary dormancy is removed under the same conditions as the primary one.

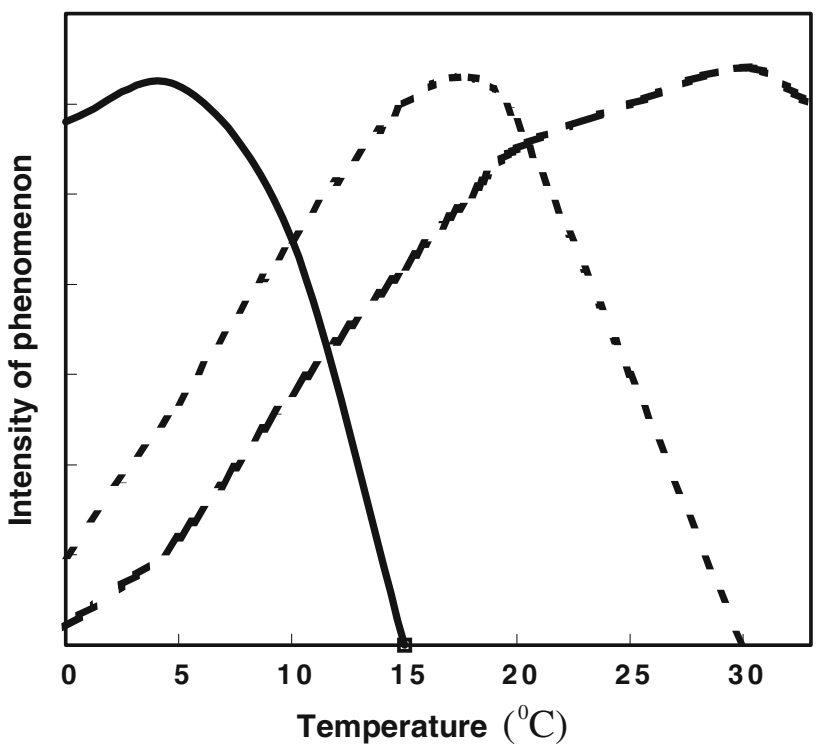

Fig. 1 Schematic presentation of temperature effects on breaking of dormancy in apple embryo (solid line), germination sensu stricto (dotted line) and growth (broken line), after Côme (1980/81)

\section{Light}

The cold-mediated removal of dormancy in intact seeds is independent of light conditions. Also non-dormant seeds germinate as well in darkness as in light. The germination of partly dormant seeds (stratified for 70 days) is, however, stimulated by light (Lewak and Smoleńska 1968). It has been demonstrated that the phytochrome system is involved in that effect. Dormant imbibed seeds do not germinate at ambient temperatures, but slow germination of embryos isolated from such seeds can be strongly stimulated (by up to 60\%) by light (Smoleńska and Lewak 1971). Seedlings grown from light-stimulated dormant embryos show, however, several developmental anomalies (Côme 1970; Wyzińska and Lewak 1978; Bogatek et al. 1991), described in "Conclusions, questions, and perspectives" of this paper, which indicates an incomplete removal of embryonic dormancy.

\section{Oxygen}

Oxygen affects the germination of isolated dormant apple embryos; they germinated better under anaerobic conditions than in air, and an increasing $\mathrm{O}_{2}$ concentration augmented its inhibitory effect on the germination (Côme et al. 1985). Atmosphere containing 50\% of $\mathrm{O}_{2}$ arrested completely germination. On the other hand, the non-dormant embryos are insensitive to oxygen. The inhibitory effect diminished in parallel to dormancy elimination. It has been demonstrated that $\mathrm{O}_{2}$ affects the second phase of germination (germination sensu stricto, see "Temperature"), but not the last one (growth of the radicle). 


\section{Hormones and other regulators affecting apple embryonic dormancy}

\section{Auxins}

The presence of three auxin-like substances in apple seeds was proposed as early as in 1957 (Luckwill 1957). Then ethyl-3-indolylacetate and 3-indolylacetylaspartate were identified in the same material (von Raussendorf-Bargen 1962). However, no free auxins were found in dormant seeds (Luckwill et al. 1969). Also Mousdale and Knee (1981) observed an important drop in IAA level in apple seeds during fruit ripening down to an insignificant value in mature seeds. On the other hand, Kopecky et al. (1975) noted a certain auxin-like activity in partly cold-stratified apple seeds. The absence of free IAA in dormant seeds and in seeds submitted to cold treatment was finally confirmed 20 years later (Dziewanowska and Lewak 1987). The free hormone appeared, however, in imbibed seeds incubated at $25^{\circ} \mathrm{C}$, under the conditions unfavorable for dormancy removal. This last observation seems to be consistent with an earlier opinion of Nikolaeva (1967) that in some seeds a supraoptimal auxin concentration is involved in the maintenance of deep dormancy. Exogenous $1-{ }^{14} \mathrm{C}$ IAA, taken up by isolated apple embryos, was found to be rapidly converted into conjugates with aspartate and short peptides containing an aspartate moiety (Dziewanowska and Lewak 1987). These observations indicate that auxin is not involved in the removal of apple embryonic dormancy.

\section{Gibberellins}

Gibberellins $\mathrm{A}_{4}$ and $\mathrm{A}_{7}$ were first identified in immature apple seeds by Dennis and Nitsch (1966). The presence of the same two hormones in mature, dormant seeds was then detected, and changes in their levels during dormancy removal were recorded (Sińska and Lewak 1970). Furthermore, the gibberellins $\mathrm{GA}_{9}$ and $\mathrm{GA}_{8}$ were identified in trace amounts in the same material (Sińska et al. 1973; Bianco and Bulard 1980). In immature apple seeds, the presence of other gibberrelins $\left(\mathrm{GA}_{5}\right.$ and/or $\mathrm{GA}_{6}$; Dennis 1976) was also postulated as well as that of $\mathrm{GA}_{63}$ in immature fruits (Avanzi et al. 1988), but these results were never confirmed. A stimulatory effect of $\mathrm{GA}_{4}, \mathrm{GA}_{7}$ and also that of $\mathrm{GA}_{3}$ on germination of isolated apple embryos was described (Kamiński and Pieniążek 1968; Lewak et al. 1970; Zhang and Lespinasse 1991). The level of gibberellin $\mathrm{A}_{7}\left(\mathrm{GA}_{7}\right)$ in dormant seeds was tenfold higher than that of $\mathrm{GA}_{4}$, and did not change significantly during almost entire period of cold stratification. However, the content of $\mathrm{GA}_{4}$ rose dramatically (more than 1,000 times) during the first 4 weeks of treatment, and then decreased to the initial value (Sińska and Lewak 1970). Dennis et al. (1980) contested the value and even the credibility of those data, but more recent experiments, performed with the use of instrumental methods (GC-MS), fully confirmed the earlier results (Halińska and Lewak 1987). In addition, a similar pattern of changes in the contents of both main apple seed GAs was observed in isolated embryos during culture. Under these conditions, the transient increase in $\mathrm{GA}_{4}$ was shown to be light-dependent and suppressed by a gibberellin biosynthesis inhibitor, AMO 1618 (Smoleńska and Lewak 1971).

The treatment of isolated dormant apple embryos with gibberellins $\mathrm{A}_{4}, \mathrm{~A}_{7}$ or $\mathrm{A}_{9}$ resulted in substantial stimulation of germination. Nonetheless, the treatment could not completely reproduce the effect of chilling; the rate of germination and its final value were markedly lower than those of non-dormant (stratified) non-treated embryos, and the secondary symptoms of dormancy (asymmetry in growth and greening of cotyledons, "Conclusions, questions, and perspectives") remained in germinated embryos (Sińska and Lewak 1970; Bulard 1985).

The involvement of gibberellins in the cold-mediated removal of dormancy in apple seeds has been demonstrated in a series of experiments where the intensity of incorporation of $2-{ }^{14} \mathrm{C}$ mevalonate (MVA) into $\mathrm{GA}_{4}$ was determined at various periods of cold stratification (Sińska and Lewak 1977). The intensity increased sharply between days 10 and 20 of stratification, and then it decreased; accumulation of $\mathrm{GA}_{4}$ stopped at day 50. The incorporation peak preceded by ca. 10 days the maximum $\mathrm{GA}_{4}$ level. Moreover, AMO 1618 (inhibitor of GA synthesis) inhibited to a high degree the incorporation of MVA into $\mathrm{GA}_{4}$, accumulation of the gibberellin as well as the germination of embryos. The inhibition of germination by AMO 1618, reaching $70 \%$ at the beginning of stratification, declined gradually, and completely disappeared in embryos isolated from seeds stratified for longer than 70 days.

The de novo biosynthesis of gibberellins is not the only process that is involved in changes of the free hormone level. The presence of bound (conjugated) gibberellins in apple seeds was demonstrated (Halińska and Lewak 1978; Bianco and Bulard 1980), and changes in their levels during dormancy removal and embryo culture were determined (Halińska and Lewak 1987). The presence of two classes of GA conjugates was evidenced: (1) glycosylated GAs releasing free hormones on $\beta$-glucosidase digestion and (2) GAs bound with amino acids or/and short peptides liberating free GAs after treatment with ficin. The interdependence observed between the changes in free and conjugated GAs suggested that formation and hydrolysis of conjugates is involved in the control of the physiologically active levels of free $\mathrm{GA}_{4+7}$ and $\mathrm{GA}_{9}$.

Changes in the levels of free GAs as well as those of GA-conjugates were also determined separately in 


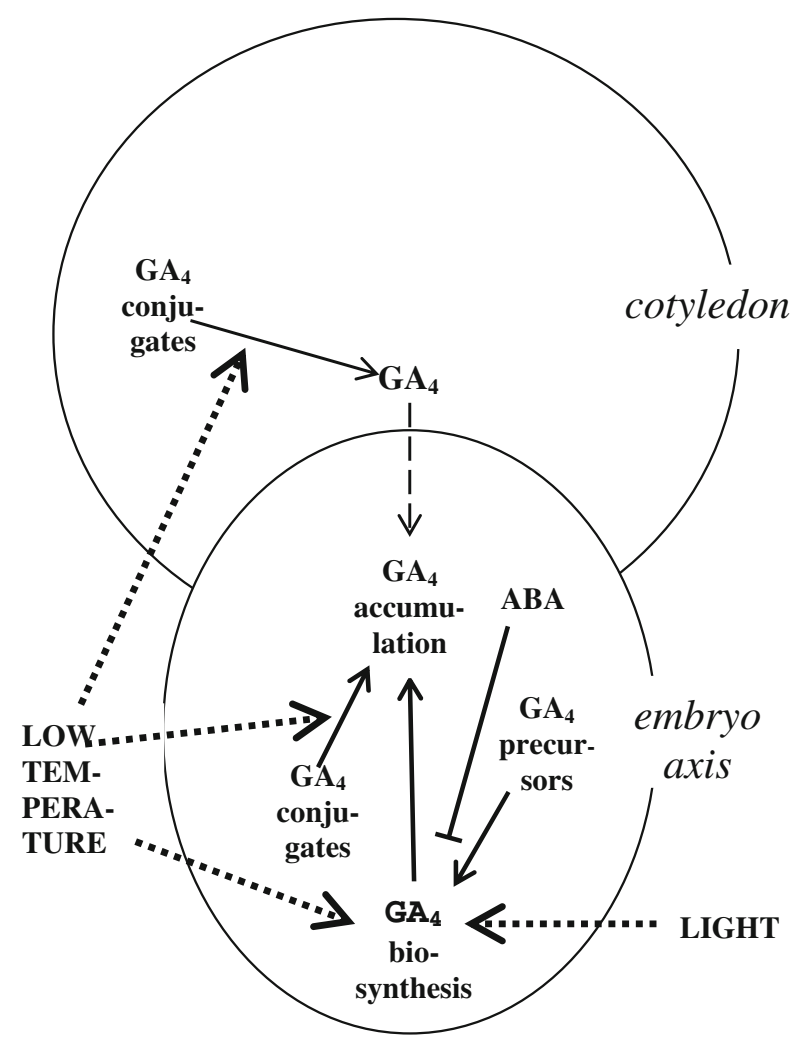

Fig. 2 Schematic presentation of the control of $\mathrm{GA}_{4}$ level in apple embryonic axis by low temperature of seed stratification and by light in cultured embryos. Mark - I on an arrow indicates inhibitory effect of $\mathrm{ABA}$

embryonic axes and in cotyledons of apple seeds during cold-mediated dormancy removal (Halińska et al. 1987). The highest GAs level in both organs was found after 30 days of stratification, the concentration in axes being 700 times higher than in cotyledons. A comparison of the changes in free and conjugated $\mathrm{GA}_{4+7}$ levels during stratification allowed us to conclude that the accumulation of free hormone in the axes was due to its release from conjugates localized in axes (ca. 40\%) and in the cotyledons (ca. 20\%). The rest (40\%) of the free hormone pool in the axes originated from de novo biosynthesis. These relations are schematically presented in Fig. 2. On the other hand, there was no difference in the pattern of changes in free and conjugated $\mathrm{GA}_{9}$ levels in axes and cotyledons; both increased markedly at the end of stratification. In these two organs, free $\mathrm{GA}_{9}$ seems to be synthesized and, in parallel, released from conjugates, but no translocation of free or bound $\mathrm{GA}_{9}$ between axes and cotyledons has been observed.

\section{Abscisic acid}

Rudnicki first identified abscisic acid (ABA) in apple seeds in 1969, and demonstrated its inhibitory effect on their germination. The same effect was noted simultaneously by Kefeli et al. (1969), whereas Subbaiah and Powell (1987) confirmed later the identification of ABA using instrumental methods. The concentration of ABA in the endosperm and seed coat exceeded threefold that in embryo axis and cotyledons. A few years after the discovery of ABA in apple seeds, relatively high amounts of its conjugate, $\beta$-D-glucopyranose ester, as well as those of an ABA catabolic product, dihydrophaseic acid 4'-O- $\beta$-Dglucopyranoside, were found in the same material (Bulard et al. 1974; Milborrow and Vaughan 1979, 1982). In dormant embryos the highest concentration of free ABA was found in embryo axis, whereas the conjugate was accumulated mainly in the cotyledons. The relatively high level of ABA in dormant seeds sharply decreased during the first 3 weeks of stratification to a concentration undetectable by bioassays (Rudnicki 1969). The decrease was due partly to its catabolism (formation of the conjugate) and partly to the leaching out to the medium (Barthe and Bulard 1982, 1983). Both phenomena were independent of the temperature (Balboa-Zavala and Dennis 1977; Subbaiah and Powell 1992; Barthe and Bulard 1987).

A close relation was found between the level of free ABA in apple embryos and the depth of their dormancy (Thévenot et al. 1987; Le Page-Degivry and Bulard 1979). Moreover, exogenous ABA induced a secondary dormancy in non-dormant embryos, and the concentration of the hormone needed to be applied in order to prevent the germination increased in relation to the length of the previous cold treatment (Rudnicki et al. 1971). All these observations evidence an important role played by ABA in the control of apple embryo dormancy.

The role of ABA in the control of dormancy in apple seeds was re-appraised by Singh and Browning (1991). They determined changes in the hormone concentration during stratification and during the control treatment of imbibed seeds with warm temperature, separately in testa, cotyledons, and embryo axes. The earlier-described (Rudnicki 1969) decrease in ABA content during the initial period of cold stratification was found to be attributed mainly to the changes in embryo axes, and a linear dependence between the log of ABA level in axes and the number of days for $50 \%$ of embryos to germinate was demonstrated. This dependence did not hold in axes isolated from embryos stratified for over 50 days when a rise in ABA concentration in axes and increased seed germinability were observed. The authors interpreted this observation as a result of a decreased sensitivity of axes toward ABA. Although the data of Singh and Browning strongly supported the role of ABA in the control of dormancy in apple embryo axis, they did not provide convincing arguments for the involvement of this hormone in 
the role of testa and cotyledons in the dormancy of an intact seed.

\section{Cytokinins}

The cytokinin (CK) activity was determined in apple seeds already in 1975, independently by Kopecky et al. and by Borkowska and Rudnicki. In both laboratories, a similar pattern of the CK-like activity changes during stratification of seeds was found; the activity rose during the first 5 weeks, reached a maximum after ca. 40 days of the treatment, and then declined. Borkowska and Rudnicki (1975) also determined changes in conjugated cytokinin level (CK-like activity released upon acid hydrolysis) during stratification. Their results indicated that the rise in the activity of free CKs during the first 3 weeks of stratification could be due to the conjugate degradation.

The apple seed cytokinins have never been identified. However, several attempts were undertaken to characterize the CKs in other apple tissues (Letham and Williams 1969; Obrenovic 1977; Takeno et al. 1982). Chromatographic comparison of purified active substances with standards allowed the presence of zeatin, zeatin riboside, zeatin ribotide, and zeatin- $O$-glucoside (a conjugate), to be postulated in apple. The role of CKs in the removal of embryonic dormancy in apple seeds is evidenced not only by the above-mentioned changes in the activity of endogenous hormones but also by their effects on germination of isolated embryos. Synthetic CKs (kinetine and benzyladenine) stimulated germination of dormant embryos (Zhang and Lespinasse 1991) and of embryos stratified no longer than for 30 days, similar to GAs (Lewak and Bryzek 1974; Lewak 1980).

\section{Ethylene}

The effects of the volatile substances emitted by apples on germination of non-dormant embryos were investigated by Paillard (1974). Ethylene inhibited the germination only slightly, whereas the inhibition exerted by other volatiles was relatively very strong. This observation can explain why the dormancy in seeds kept inside apples is stronger than that in isolated seeds or embryos.

That ethylene concentration rises in apple seeds submitted to cold stratification and in seeds stored in fruit at $2^{\circ} \mathrm{C}$ was evidenced a little later (Kępczyński and Rudnicki 1976). The content of ethylene in the seeds rose threefold during the first 4 months of stratification, whereas in the seeds of cold-treated fruits the ethylene content stopped increasing after 6 weeks of cold storage and was maintained on the same level until week 22, being lower by one-third than that in isolated stratified seeds. A certain correlation was found between the concentration of endogenous ethylene in seeds and their germinability. Moreover, exogenous ethylene hastened germination of isolated dormant embryos (Kępczyński and Rudnicki 1977).

The rise in endogenous ethylene concentration in seeds was attributed to its production by embryos, as evidenced by experiments with the use of ethylene traps and inhibitors of its biosynthesis (Kępczyński et al. 1977). The same experimental approach proved the role of ethylene in dormancy release in apple embryos; inhibitors of ethylene biosynthesis and action markedly inhibited the germination, and the effect was stronger in embryos stratified for a short time than in the less dormant ones (Kępczyński et al. 1977). The inhibition of embryo germination was shown to be reversed by ethephon (a source of ethylene) when applied to seeds (Sińska and Gladon 1984). These results were not fully confirmed by Ozga and Dennis (1989). They called into question the role of ethylene in the control of dormancy and germination in apple seeds.

\section{Jasmonic acid}

Jasmonic acid (JA) was identified in apple embryos in 1994 using GC-MS and immunological methods (Ranjan et al. 1994). Its level increased during the first 30 days of stratification by two orders of magnitude, then dropped and rose again to reach a second, smaller maximum around day 70 (threefold the initial level). The pattern of changes of bound (conjugated) JA level was similar to that of free JA during its first sharp rise. Therefore, it was suggested that de novo synthesis is responsible for the initial rise in both free and bound hormone levels. The second rise of free JA content was accompanied by an equivalent decrease in its conjugates, so for that rise the release of JA from its inactive forms was postulated. The chemical nature of the apple seed JA conjugates remains unknown.

The JA was shown to promote germination of dormant apple embryos (Ranjan and Lewak 1992). On the other hand, the germination was strongly inhibited by SHAM (salicylhydroxamic acid, an inhibitor of JA biosynthesis). Both effects disappeared in embryos stratified longer than for 40 days, when the level of endogenous JA decreased after its first maximum (Ranjan et al. 1994). These data present strong arguments for an involvement of JA in the control of dormancy in apple embryos. Moreover, JA inhibited the elongation growth of cotyledons of isolated dormant embryos in culture, and the cotyledon being in contact with the culture medium was more strongly affected (Bogatek et al. 2002). This explains the observation that JA-treated embryos showed almost no asymmetry 
in growth of cotyledons which is one of the symptoms of embryonic dormancy.

Cyanides

Free hydrogen cyanide was found in apple seeds submitted to stratification (Dziewanowska et al. 1979b) as well as in isolated dormant embryos in culture (Bogatek et al. 1991). In both cases, it was produced mainly by hydrolysis of amygdaline, a cyanogenic glucoside present in fairly large amounts in seeds and known for more than a century (Lehmann 1874). A second cyanogenic glucoside, prunasine, was identified in the same material in much lower amounts (Dziewanowska et al. 1979c). Additionally, in apple seeds, similar to other plant materials, $\mathrm{HCN}$ is certainly produced from aminocyclohexane carboxylic acid (ACC) as a co-product of ethylene formation (Peiser et al. 1984). The maximum concentration of free $\mathrm{HCN}$ appeared in apple embryos around the 15th day of seed stratification.

Hydrogen cyanide and its alkaline salts (e.g., KCN) applied to apple seeds or isolated embryos have a dual action (Dziewanowska et al. 1979a; Perino and Côme 1981) as they do in other experimental systems (Siegień and Bogatek 2006). When present constantly in the medium, cyanide inhibited germination, leading eventually to the death of the embryo. On the other hand, a short treatment with gaseous HCN had a stimulatory effect on germination of dormant apple embryos and provoked the elimination of secondary symptoms of dormancy (e.g., asymmetric growth and greening of cotyledons). Although a short treatment with $\mathrm{KCN}$ stimulated the germination of dormant apple embryos (Perino and Côme 1991), it seems to be of some interest that the beneficial effect of gaseous $\mathrm{HCN}$ occurred only in light or in gibberellin-treated embryos (Dziewanowska and Lewak 1982; Bogatek et al. 1991). All the above observations indicate that cyanide is involved in the control of dormancy in apple seeds.

\section{Nitric oxide}

Nitric oxide (NO), an important regulatory compound, is present in all living organisms and is involved in the control of many different processes, including seed germination (for a review see, e.g., Beligni and Lamattina 2000; Neil et al. 2003). NO has not yet been identified in apple seeds. However, the treatment of dormant apple embryos with sodium nitroprusside, a NO producing chemical, markedly stimulated their germination (Bogatek and Gniazdowska 2006; Gniazdowska et al. 2007). The effect was comparable to that of cyanide in respect to elimination of cotyledon asymmetry in growth and greening.
Polyamines

The presence of three main polyamines (biogenic amines, PAs), putrescine, spermidine, and spermine, in apple seeds was demonstrated in 1991 by Sińska and Lewandowska. The levels of all these PAs decreased during cold-mediated removal of embryo dormancy (stratification). Spermine, present in seeds at the highest concentration, significantly inhibited germination when applied to isolated embryo, while the other two PAs had a stimulatory effect. Moreover, spermine reduced the production of ethylene in apple embryos in contrast to putrescine and spermidine which had no effect. The authors concluded that all three PAs are involved in the control of dormancy, but their modes of action are different; spermine contributes to the regulation of dormancy maintenance by preventing ethylene synthesis, and the other PAs participate in dormancy removal, independently of ethylene.

\section{Phenolics}

Phloridzin (phloretin $\beta$-D-glucoside) is the most abundant monomeric phenol in apple seeds. It amounts up to $8 \%$ of dry matter and in dormant seeds is located, together with condensed tannins, in the seed coat mainly (Dziewanowska et al. 1974). Its level in the integument decreased to trace amounts during the first 20 days of stratification (Pieniążek and Grochowska 1967; Bogatek et al. 1976), whereas in embryos it started to increase sharply on day 20 and reached a maximum at the end of stratification (day 80). In addition to phloridzin, chlorogenic acid, and hydroxylated cinnamic acids were identified, mostly in the coat (Durkee and Poapst 1965). The huge concentration of phenolics in the coat has been postulated to play a role in maintaining the dormancy of the embryo (Côme 1968). On the other hand, lower concentrations of phloridzin, its aglycone phloretin and other phenolics present in the embryo (e.g., chlorogenic acid) may play a secondary role in the control of dormancy, affecting the activity of important enzymes and thus at least some of the processes cardinal for the onset, maintenance, or removal of dormancy (e.g., Dziewanowska and Lewak 1975).

\section{Regulatory complex involved in dormancy removal}

The changes in the levels of hormones and some other regulators in apple seeds during dormancy removal under conditions of stratification at $5^{\circ} \mathrm{C}$ are schematically presented in Fig. 4. As discussed above, all of them affect dormancy, and one can consider them collectively as a regulatory complex controlling the course of dormancy elimination. There are three distinct phases during this course characterized by different, changing hormonal 
balance. In a dormant, imbibed embryo, the lowest level of growth-stimulating regulators (GAs, CKs, JA, and ethylene) and the highest concentration of ABA-the only potent inhibitor of germination characterized in these seeds-were observed. During the first 20 days of cold treatment, ABA disappeared; a dramatic burst of $\mathrm{HCN}$ took place around day 15 of stratification; and a gradual increase of the levels of all stimulators began. The next phase was characterized by a sharp rise in GAs, CKs, and JA levels. All these hormones reached a maximum between the 30th and 40th days of stratification. During this time, a second, moderate maximum of HCN was observed. During the last phase of seed after-ripening, the amounts of all the studied regulators decreased to the levels comparable to those in dormant seeds. Only JA showed a second, slight maximum during the last phase of stratification. The changes in the emission rate of ethylene did not follow the phasic character of hormone-level changes described above; it rose slowly throughout stratification.

A comparison of the germination rate of embryos isolated from apple seeds after different periods of cold treatment (Fig. 3) with the data in Fig. 4 indicates that a significant decrease in the depth of dormancy (increase in embryo germinability) starts when ABA has disappeared in the embryos. In parallel to the ABA level decrease, the concentrations of GAs and CKs as well as that of JA begin to increase and reach their maxima when $\mathrm{ABA}$ is no more present (ca. day 30). From this crucial moment, the rate of embryonic dormancy removal accelerates, being the highest between the 30th and 50th days of stratification (Fig. 3). Afterward, the levels of all stimulatory hormones gradually decrease. This observation agrees with the Khan's (1975) concept of designated, selective functions of hormones in

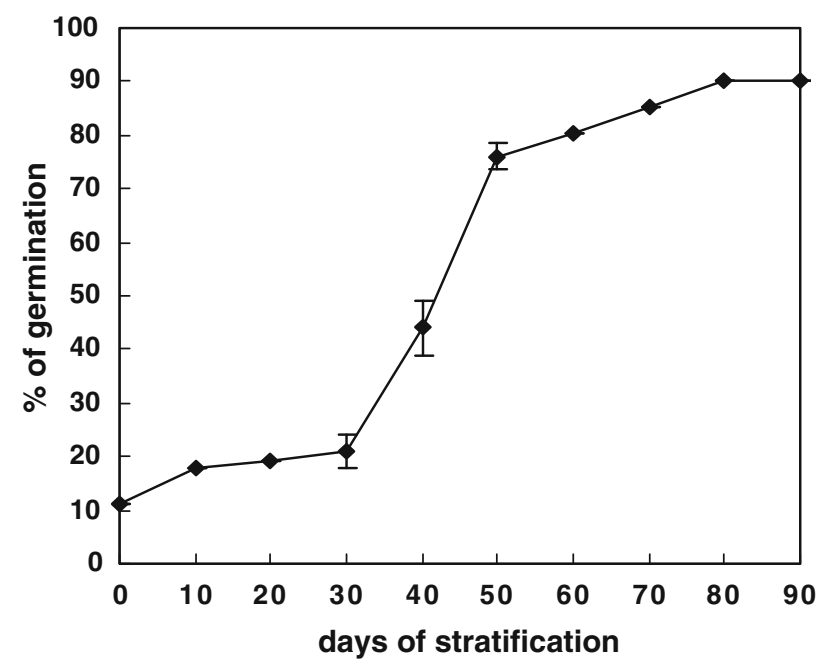

Fig. 3 Germination after 10 days at $25^{\circ} \mathrm{C}$ of apple embryos isolated from seeds stratified for different periods at $5^{\circ} \mathrm{C}$. Vertical bars indicate maximum standard errors

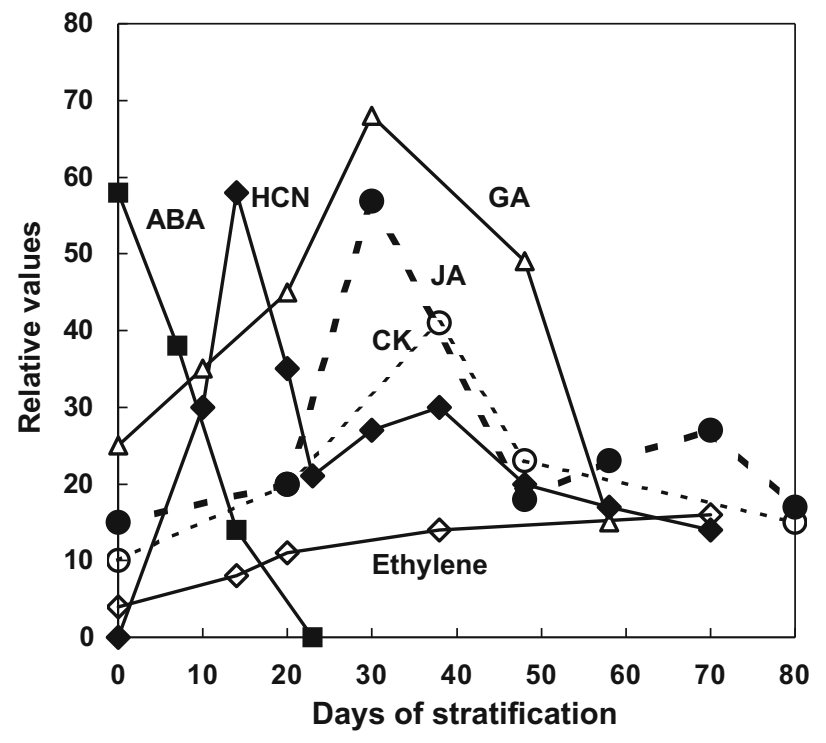

Fig. 4 Schematic presentation of changes in levels (relative concentrations) of main growth regulators in apple seeds during the cold $\left(5^{\circ} \mathrm{C}\right)$ stratification. $A B A$ abscisic acid, ethylene rate of $\mathrm{C}_{2} \mathrm{H}_{4}$ emission, $C K$ free cytokinins, $G A$ free gibberellins $\mathrm{A}_{4}$ and $\mathrm{A}_{7}, H C N$ free hydrogen cyanide, $J A$ jasmonic acid

the control of seed germination and dormancy. According to that concept, the completely, deeply dormant embryos are unable to germinate because of a too high level of ABA (inhibitor) and, simultaneously, too low concentrations of $\mathrm{GA}, \mathrm{CK}$, and/or JA. Gibberellins probably play the primary role, whereas other stimulators play permissive roles for germination. The cardinal metabolic processes of germination, initiated by the appropriate balance of the hormonal complex, can be continued during the last phase of dormancy removal when the concentrations of all hormones drop down.

An additional piece of evidence for the presence of a regulatory complex that controls embryonic dormancy removal in apple seeds is the observation of synergistic or additive effects of different factors affecting germination of dormant embryos. Light interacts synergically with JA, and the same kind of effect has been observed for $\mathrm{ABA}$ and light, JA and ABA, and HCN and ABA. On the other hand, the interaction between light and GA has an additive character. Similarly, additivity has been observed between the effects of GA and JA (Ranjan and Lewak 1994). These relations allow one to speculate whether the given two factors share the same chain of events involved in dormancy removal (synergism) or act on different, independent routes (additivity).

As mentioned above, there are data indicating the mechanisms involved in the changes of the levels of particular regulators studied. At any given time, the current levels of active hormones and other regulators in apple seed obviously result from an equilibrium between the 
intensities of their biosynthesis, degradation, and reversible inactivation (formation and breakdown of conjugates). Also translocation between seed parts (organs) plays a role in establishing concentration of a given regulator in a target cell.

The biosynthetic pathways of plant growth regulators have never been investigated in apple seeds. Nevertheless, there are data concerning hormone synthesis in fruits; for example, some genes encoding enzymes involved in ethylene synthesis have been identified, and their cDNA sequenced (Dong et al. 1991, 1992). There is, however, no good reason to assume that the main biosynthetic pathways of growth regulators in apple seeds are different from those established for other plant material. Moreover, in apple seeds, as in other plant systems, the presence of one regulator can affect some step(s) in the biosynthesis of another one. It has been established that spermine counteracts the production of ethylene in apple seeds (Sińska and Lewandowska 1991). Gibberellin and cytokinin treatments stimulated ethylene production in cultured isolated embryos, and the inhibition of embryo germination by inhibitors of ethylene synthesis (aminoxyacetic acid and aminoethoxyvinylglycine) was counteracted by $\mathrm{GA}_{3}$ and CK (Sińska 1989). Ethylene synthesis is also stimulated by nitric oxide treatment of embryos, and inhibitors of ethylene synthesis reversed the NO-induced stimulation of germination (Gniazdowska et al. 2007). ABA strongly inhibited accumulation of $\mathrm{GA}_{4}$ during seed stratification as well as during the culture of isolated embryos (Rudnicki et al. 1972); the effect was less pronounced for $\mathrm{GA}_{7}$. On the other hand, gibberellin treatment decreased the level of ABA in apple fruits (Wills et al. 1976). Phloridzin and phloretin present in apple seeds during the end period of stratification decreased $\mathrm{HCN}$ production by competitive inhibition of amygdalinase activity (Dziewanowska et al. 1979c). It has also been found that methyl jasmonate strongly affects the ethylene (and ACC) production in apples, the effect being dependent on fruits maturity (Saniewski et al. 1987).

\section{Metabolic events occurring during dormancy removal}

Dormant apple seeds dry matter contains 22-26\% of lipids, mostly triacylglycerols but also free fatty acids (mainly linolenic; Lu and Foo 1998), and up to $5.5 \%$ of proteins as main storage materials. It also contains ca. $2-4 \%$ of soluble sugars and ca. $8 \%$ of pentosanes and a small amount of starch which is localized almost exclusively in the seed coat (Wierszyłłowski 1960; Kawęcki 1970). Therefore, the mobilization and transformations of these reserves have been considered as processes unquestionably cardinal for germination of these seeds, whereas the control of these processes have been considered as an important element in the metabolic regulation of dormancy.

\section{Catabolism of lipids}

The reserve triacylglycerols form lipid bodies in every tissue of the apple embryo. During stratification they gradually disappear. In embryo axis, the disappearance of lipid bodies starts earlier than in cotyledons, and it was not observed during the control treatment at $20^{\circ} \mathrm{C}$ (Dawidowicz-Grzegorzewska 1989). Storage lipids are hydrolyzed by lipases during removal of seed dormancy, during stratification and early germination. The released fatty acids are then converted to acetyl-CoA, which either enters the tricarboxylic acid cycle producing metabolic energy and important intermediates (Raymond et al. 1992), or is used for the synthesis of saccharides (gluconeogenesis).

In apple seeds submitted to stratification, two lipidhydrolyzing enzymes are active. They differ in their temperature and $\mathrm{pH}$ optima, location in the seed, and periods of maximum activity (Smoleńska and Lewak 1974). The maximum activity of acid lipase (AcL) is observed at day 40 of stratification, and its temperature optimum is at $5^{\circ} \mathrm{C}$, the same as the temperature optimum for stratification. The enzyme is located in the embryo axis exclusively. The activity of alkaline lipase (AlkL) appears ca. 20 days later; its temperature optimum is at $30^{\circ} \mathrm{C}$, and it is active mostly in the cotyledons (Żarska-Maciejewska and Lewak 1976; Żarska-Maciejewska 1992).

The degradation via $\beta$-oxidation of fatty acids released by lipases was observed mainly in cotyledons. Its intensity increased in parallel to the increase of the lipolytic activity in cotyledons during the culture of apple embryos (Bogatek et al. 1999). Also changes in the activity of isocitrate lyase, the key enzyme of the glyoxylate cycle, paralleled the changes in the AlkL activity in cotyledons (Bogatek et al. 1989; Bogatek and Lewak 1991). These data indicate that during dormancy removal and early germination of apple seeds, similar to other oily seeds, at least a fraction of storage cotyledonous lipids is converted into saccharides that play the role of "secondary reserves", easily available for catabolic processes; they are used for generation of energy and intermediates when the needs of the germinating seed are the highest (Bewley and Black 1983).

Besides triacylglycerols, also phospholipids have been characterized in apple seeds, and the changes in their levels during dormancy removal are recorded. The pattern of the changes seemed not to be temperature dependent; therefore, the phospholipid metabolism was not considered a process cardinal for dormancy removal (Nguyen et al. 1984, 1987). 
Carbohydrate metabolism

The soluble sugars present in the embryos are mainly the oligosaccharides sucrose and raffinose, and the monosaccharides glucose and fructose in amounts lower by one order of magnitude. The oligosaccharides are hydrolyzed during dormancy removal by appropriate glycosidases. In embryonic axes, sucrose, present in micro molar concentration, is hydrolyzed by both acid and alkaline invertases (AcI and AlkI, respectively). In the cotyledons, where sucrose concentration is tenfold higher, only the alkaline (cytosolic) invertase is active (Bogatek et al. 1999). An enzyme hydrolyzing raffinose (acid raffinose hydrolase) has also been found in germinating embryos, but generally the levels of oligosaccharides, as well as those of glucose and fructose, seem not to decrease during seed stratification and even, according to some data, they slightly increase (Popov 1967; Kawęcki 1970). The fact that an addition of sucrose to the stratification medium accelerated the removal of seed dormancy may present an argument for a role of sugar catabolism in the process (Daskalyuk 2002). On the other hand, the observation that the dormancy of isolated apple embryos cultured in the presence of sucrose is better expressed than in the absence of this sugar (Barthe and Bulard 1982) indicates otherwise.

Monosaccharides in apple seeds are degraded during dormancy removal via both widespread catabolic ways: glycolysis (Embden-Meyerhof-Parnas pathway) and the pentose phosphate oxidative pathway (PPP). This has been evidenced by the demonstration of activities of key enzymes of these pathways: pyruvate kinase (PK) and phosphofructokinases (PPi- and ATP-dependent, PPi-PFK and ATP-PFK, respectively) for glycolysis, and glucose-6phosphate dehydrogenase (G6PDH) for PPP (Bogatek and Lewak 1988; Bogatek et al. 1989; Bogatek 1995) and by the determination of the ratios of ${ }^{14} \mathrm{CO}_{2}$ derived from ${ }^{6-}{ }^{14} \mathrm{C}$-glucose to ${ }^{14} \mathrm{CO}_{2}$ from $1{ }^{1-}{ }^{14} \mathrm{C}$-glucose $\left(\mathrm{C}_{6} / \mathrm{C}_{1}\right.$ ratio). Changes in this ratio during seed stratification indicate that glycolysis is the dominant way of sugar catabolism during the first few days of stratification and in embryos stratified for 50 days or longer, whereas PPP dominates between days 10 and 50 (Bogatek and Lewak 1978, 1988). It is of some interest that under control conditions (incubation of imbibed seeds at $25^{\circ} \mathrm{C}$ ) which do not result in dormancy elimination, the high initial intensity of glycolysis decreased during the first 10 days, and the activity of PPP did not appear. A similar situation was observed for cultured dormant embryos (Bogatek et al. 1989). One can conclude that relatively high production of ATP takes place at the beginning of the first phase of dormancy removal and during the induction of growth (last phase), and that the important intermediates of PPP (i.e., pentoses) are produced mainly during the second, catabolic phase (germination sensu stricto). The importance of PPP for the dormancy removal during the phase of germination sensu stricto has been confirmed by the use of inhibitors of respiration (KCN and SHAM), of glycolysis and TCA cycle (NaF and malonate, respectively) (Perino and Côme 1991). However, the occurrence of the activity of G6PDH, the key enzyme of PPP, is restricted to cotyledons, whereas ca. 1/3 of PK activity, a glycolytic enzyme, was found in embryo axes and ca. $2 / 3$ in cotyledons. The activity of another glycolytic enzyme, PPi-PFK, was shown to be controlled in embryo axes by fructose 2,6-bisphosphate, which is synthesized in this organ (Bogatek 1995).

Small amounts of starch were detected in the axis of the dormant embryo. They disappeared within 10 days of cold stratification, including statolith starch in the root cap (Zagórski and Lewak 1980). Then the starch content in embryo axis increased throughout removal of seed dormancy (Dawidowicz-Grzegorzewska and Lewak 1978).

Phosphatases are involved in several metabolic processes in seeds, including sugar catabolism. Total acid phosphatase activity changes in apple seeds along stratification, decreasing during the first 20 days, then increasing to attain a maximum on day 60 , and after a second drop rising again in germinating seeds (Rychter et al. 1971, 1972).

\section{Protein metabolism}

Total soluble protein content in apple seeds increases slowly during the first 60 days of stratification, and then remains unchanged until the end of cold treatment. Protein biosynthesis (incorporation of radioactive amino acids), slow at the beginning, sharply increases after day 60 (Lewak et al. 1975). A sharp rise in RNA content in embryos is observed a few weeks earlier (at day 30), whereas the ability to synthesize RNA (incorporation of $\left[{ }^{3} \mathrm{H}\right]$-uridine) increases slowly during the whole stratification period (DawidowiczGrzegorzewska and Żarska-Maciejewska 1979).

Storage proteins are located in the embryo axis and in the cotyledons, mainly in protein bodies composed of a homogenous dense matrix with several crystalline globoids. Protein bodies disappear gradually during seed stratification, first in the axis and then in the cotyledons and finally are replaced by vacuoles (Dawidowicz-Grzegorzewska and Żarska-Maciejewska 1979; Dawidowicz-Grzegorzewska 1989). Similarly, protein bodies disappear in cultured isolated embryos pretreated with low temperature $\left(5^{\circ} \mathrm{C}\right)$, and an increase of free amino acids parallels the increase in their germinability. On the other hand, in apple embryos isolated from seeds kept inside fruits at $0^{\circ} \mathrm{C}$ for 4 months, under conditions of slow dormancy removal; no visible changes in protein body morphology and no changes in free amino acid level were observed. This result was 
interpreted as an argument that proteolysis could be a cardinal process for germination, but not for dormancy removal (Dawidowicz-Grzegorzewska et al. 1982).

Although the protein level in embryo axes changes very little during stratification, the polypeptide profiles change markedly. A new polypeptide appears, and the level of four others increases. At the same time, the levels of five most predominant axis proteins decrease. No such changes were observed in axes during control treatment at $15^{\circ} \mathrm{C}$, or in the cotyledons. Although these changes are probably linked with dormancy removal, since they are not observed during control treatment, their precise function remains unknown (Eichholtz et al. 1983). More recently, three polypeptides were identified in apple embryo axes (Daskalyuk et al. 1996); the content of two of them ( 44 and $46 \mathrm{kD}$ ) decreased during seed cold stratification and the third $(28 \mathrm{kD})$ increased. They were considered as indicators of the progress of stratification (depth of dormancy).

Total proteolytic activity markedly increased during the first 50 days of seed stratification, and then returned to the initial value (Lewak et al. 1975). The rise of protease activity was accompanied by a slight increase of soluble protein content, which may indicate proteolytic solubilization of insoluble reserve proteins.

The proteolytic activities in apple embryos in relation to their dormancy were studied using several synthetic substrates-amino acid $\beta$-naphtylamides and short peptides (Żarska-Maciejewska and Lewak 1983). The activities show different patterns of changes during stratification and also differences in $\mathrm{pH}$ optima. All the activities studied have a temperature optimum around $35^{\circ} \mathrm{C}$, except one that hydrolyzes peptide bonds adjacent to a cysteine residue. This activity, which appears early during stratification, is the highest at $5^{\circ} \mathrm{C}$ - the temperature optimum for dormancy removal. It is also induced by low temperature treatment, in contrast to the other proteolytic activities studied. Therefore, an important role of the cysteine aminopeptidase in cold-mediated dormancy removal was postulated, in parallel to that of acid lipase.

Several inhibitors of proteases (trypsin and papain) have been identified in apple seeds. They were purified to homogeneity, and their amino acid sequence was partly established (Ryan et al. 2003). However, their ability to inhibit native apple seed protease activities has not been studied. Therefore, their possible roles in maintaining and removal of dormancy can only be speculated upon.

\section{Energy generation}

Mature mitochondria were observed in dormant apple seeds (Dawidowicz-Grzegorzewska 1989). They become functional just after imbibition. The respiratory activity in embryos is very low at the beginning of cold treatment, and increases only slightly in the course of stratification. The respiratory capacity (respiration of cold-treated embryos measured at $25^{\circ} \mathrm{C}$ ), however, rises progressively during dormancy removal (Bogatek and Lewak 1978). Values of the respiratory quotient (RQ) indicate that in dormant embryos and in embryos kept under conditions that do not remove dormancy carbohydrates are used as the main respiratory substrates (RQ around 0.8 ), whereas under conditions of cold stratification they are replaced by lipids (RQ 0.35). At $25^{\circ} \mathrm{C}$ the oxygen uptake is limited by the presence of the seed coat, but at $5^{\circ} \mathrm{C}$ naked embryos and intact seeds consume oxygen at the same low rate (Nikolaeva 1967).

The occurrence of the alternative, cyanide-resistant pathway has been demonstrated in apple embryos as well as in isolated mitochondria, in parallel to the cytochrome path (Bogatek and Rychter 1984). The latter pathway is not saturated under conditions of cold stratification and the low requirement for oxygen. Therefore, the alternative pathway seems not to operate during cold-mediated dormancy removal, and so, it cannot be implicated in the process. The situation is changed during the last period of stratification, preceding the growth of the embryo axis (germination), when the increased oxidative metabolism requires a higher oxygen uptake.

Several enzymes involved in redox reactions have been identified in apple seeds (malate, isocitrate, alcohol and glucose-6-phosphate dehydrogenases, $O$-diphenol oxidoreductase, peroxidases, and catalases; Rychter and Lewak 1969). Among them peroxidases were studied the most extensively. The total peroxidase activity does not change during incubation of intact seeds, independently of the temperature. In cultured isolated embryos, the activity increases sharply, but the increase is better pronounced at $20^{\circ} \mathrm{C}$ than at $5^{\circ} \mathrm{C}$ (Thévenot et al. 1977). This observation suggests that peroxidases in apple seeds are not involved in the processes of dormancy removal, but rather in the growth following germination. Moreover, several proteins that exhibit peroxidase activity were visualized electrophoretically. Their number depended on the electron donor used as substrate (Rychter and Lewak 1971) and on the mode of extraction (free and bound peroxidases), but to a lower extent on the depth of embryo dormancy (Lewak 1986).

Several peroxidase and catalase isozymes were identified in apple seeds and used as markers of genetic relationships between the varieties (Korban and Bournival 1987). This study was, however, not related to seed dormancy.

\section{Environmental and hormonal control of metabolic events}

As it has been mentioned in "Environmental factors that affect dormancy in apple seeds", the main environmental 
factors that affect embryonic dormancy in apple seeds are humidity, temperature, and light. In order to control the metabolic and physiological events related to dormancy, they have to be perceived by meristems.

Perception of environmental stimuli

\section{Hydration}

It seems obvious that the immediate effects of increasing hydration on the conformation and activity of certain structures are similar in all seeds. Certainly, some structural alterations of cell membranes, resulting in an increased spacing of the phospholipid bilayer (e.g., Seewaldt et al. 1981), as well as the changes of the cell wall-plasma membrane interactions (Kohorn 2000) play an important role in initiation of metabolic events in a germinating seed. The hydration of cell colloids resulting in activation of certain enzymes seems to be, however, the most important. Enzymes that hydrolyze reserve saccharides and proteins become active very soon after imbibition of seeds. The same concerns other enzymes, e.g., those involved in protein synthesis. Hydration of mature mitochondria is a prerequisite of their activity. Similarly the residual (long-lived) mRNA becomes active at a certain degree of cell hydration. All these effects are not specific to conditions allowing removal of embryonic dormancy although soaking injuries are less pronounced at low temperatures.

\section{Temperature}

The most thoroughly studied processes in plants in relation to changing temperature are the changes in the membrane structure and properties. The transitions of the phospholipid layer from lamellar to hexagonal and from crystalline (gel) to lipid crystalline are strongly affected by temperature. They can be responsible for intercellular ion and metabolite translocations and for the accessibility of membrane enzyme proteins and thus for their activity. Therefore, they are considered as putative temperature receptors also in dormant and germinating seeds (e.g., Bewley and Black 1982).

It is tempting to assume that the main receptors of low temperature required for complete removal of dormancy in apple seeds are the enzymes exhibiting optimum activity at the same temperature as the optimum for stratification, or very close to that temperature. Such enzymes certainly include acid lipase (Smoleńska and Lewak 1974) and endoprotease that hydrolyzes peptide bonds adjacent to a cysteine residue (Żarska-Maciejewska and Lewak 1983). Similarly, certain isozymes of acid phosphatase have been shown to be less sensitive to lowering of the incubation temperature than others (Rychter et al. 1972). Despite the limited substrate specificity of this group of enzymes, this observation may indicate that the equilibrium between different reactions catalyzed by phosphatases is affected by low temperature of stratification, and thus, it can contribute in the temperature sensor system.

Obviously, the synthesis of enzymes involved in the processes cardinal for germination might also be selectively controlled by the conditions of stratification, in parallel to their direct activation (deactivation) by low temperature.

Hormones are another likely component of the system responding to the temperature stimulus in apple seeds. IAA and ABA cannot be taken into account for the reasons presented earlier ("Auxins" and "Abscisic acid"), but the increase of the level of gibberellin $\mathrm{A}_{4}$ by several orders of magnitude during the first period of stratification is certainly one of the early effects of low temperature; no such increase is observed under control (warm) conditions (Halińska and Lewak 1987). As it has already been mentioned ("Gibberellins"), the GAs increase in the embryonic axes of cold-treated seeds is due in parallel to the release of the free hormone from its conjugates, to the synthesis de novo, and also to their transport from cotyledons (Halińska et al. 1987). The first (immediate) effect of cold must be, therefore, the activation of an enzyme(s) involved in one of these processes; most probably an enzyme hydrolyzing the conjugates as indicated in Fig. 2.

There is no such evidence for an involvement of other apple seed hormones in the low-temperature sensing. However, one can postulate for cytokinins, jasmonates, ethylene, and/or cyanide, a role similar to that played by gibberellins.

\section{Light}

Light is not irreplaceable for breaking the embryonic dormancy in apple. However, as it has been mentioned earlier ("Gibberellins"), germination of dormant embryos is strongly stimulated by light, and illumination of partly stratified seeds accelerates elimination of dormancy. There is convincing evidence that in both experimental systems phytochrome is the only receptor of light. The action spectra for stimulation and inhibition of germination at 660 and $720 \mathrm{~nm}$, respectively, as well as the lack of a blue light effect, the mutual reversibility of red and far-red illuminations, and the low light intensity required for the physiological effects all point to the low fluence response mechanism (LFR) as the one responsible for the light stimulation of apple embryo germination (Lewak and Smoleńska 1968; Smoleńska and Lewak 1971).

The sensitivity of seeds toward light increased during cold treatment and disappeared in non-dormant, fully 
stratified seeds. This observation suggests an interaction between the early events triggered by light and low-temperature stimuli. On the other hand, during the culture of isolated dormant embryos, the light sensitivity was the highest on the second day, just after imbibition. This maximum was followed by a sharp increase in $\mathrm{GA}_{4}$ content (ca. threefold), which was neither observed in darkness, nor in light in the presence of a GA biosynthesis inhibitor. These results indicate that $\mathrm{GA}_{4}$ synthesis may be an immediate result of phytochrome activation by light. This conclusion is in full agreement with data obtained for other photosensitive seeds (e.g., Thomas 1992).

It seems to be of interest that jasmonate level in cultured dormant embryos also depends on light conditions. In lightcultured embryos, JA level was higher by $50 \%$ than in control ones, cultured in darkness (Ranjan and Lewak 1995).

Control of metabolic events involved in release from dormancy

The data presented above as well as the observed effects of low temperature, light, and hormone treatments on the studied enzyme activities allowed us to postulate several cause-effect relations constituting elements of the chains of events leading from the environmental stimulus to the regulation of certain cardinal processes of germination, and thus controlling the embryo dormancy.

\section{Metabolism of storage lipids}

Numerous data indicate that the environmental factors studied, hormones, and other regulators affect the activity of enzymes involved in lipid metabolism. Acid lipase (AcL) located in the embryonic axis is most active at a low temperature, and it is also activated by cold, whereas alkaline lipase (AlkL) operates in cotyledons of seeds stratified for longer periods, and appears also in cotyledons of light-cultured dormant embryos (see "Catabolism of lipids"). Nonetheless, both enzymes are activated by gibberellin treatment, and the appearance of both activities has been shown to be inhibited by AMO 1618, an inhibitor of gibberellin biosynthesis (Smoleńska and Lewak 1974; Żarska-Maciejewska et al. 1980). Similar relations (GA and AMO effects) have been demonstrated for isocitrate lyase (ICL), the key enzyme of the glyoxylate cycle (Bogatek et al. 1989). These observations, together with data presented earlier, allow the relations shown in Fig. 5 to be put forward.

Only the alkaline lipase activity was inhibited by ABA; the activity of AcL in embryos was not affected by the hormone (Ranjan and Lewak 1995). In contrast, both lipases are affected by jasmonate. Alkaline lipase activity is stimulated by JA treatment in cultured dormant embryos, in parallel to their germination, and both effects are additive to those of light. Inhibitors of JA biosynthesis (salicylhydroxamic acidSHAM and $n$-propyl gallate) inhibited germination and AlkL activity to a similar extent (Ranjan and Lewak 1992). Acid lipase was markedly stimulated by JA, but only in dormant embryos, and embryos stratified no longer than for 45 days. It seems to be of interest that the effects of both JA (stimulation) and ABA (inhibition) on the activity of both lipases were also observed in vitro when the hormones were applied to enzyme extracts (Ranjan and Lewak 1995). This observation indicates that the control of both activities by JA and ABA relies upon their activation rather than on the enzyme proteins synthesis.

The additivity of the effects of JA with those of GA and light on dormant embryo germination and on AlkL activity (Ranjan and Lewak 1992, 1994) indicates that JA affects AlkL in another way than that triggered by light and shown in Fig. 5. Moreover, the lack of additivity between the effects of JA and ABA on germination and AlkL activity (Ranjan and Lewak 1995) suggests that the site of action of ABA in the JA-initiated chain of events differs from that
Fig. 5 Schematic presentation of the sites of action of environmental factors (low temperature and light) and gibberellin in the control of lipid catabolism in apple embryos. $A c L$ and $A l k L$ acid and alkaline lipases, respectively

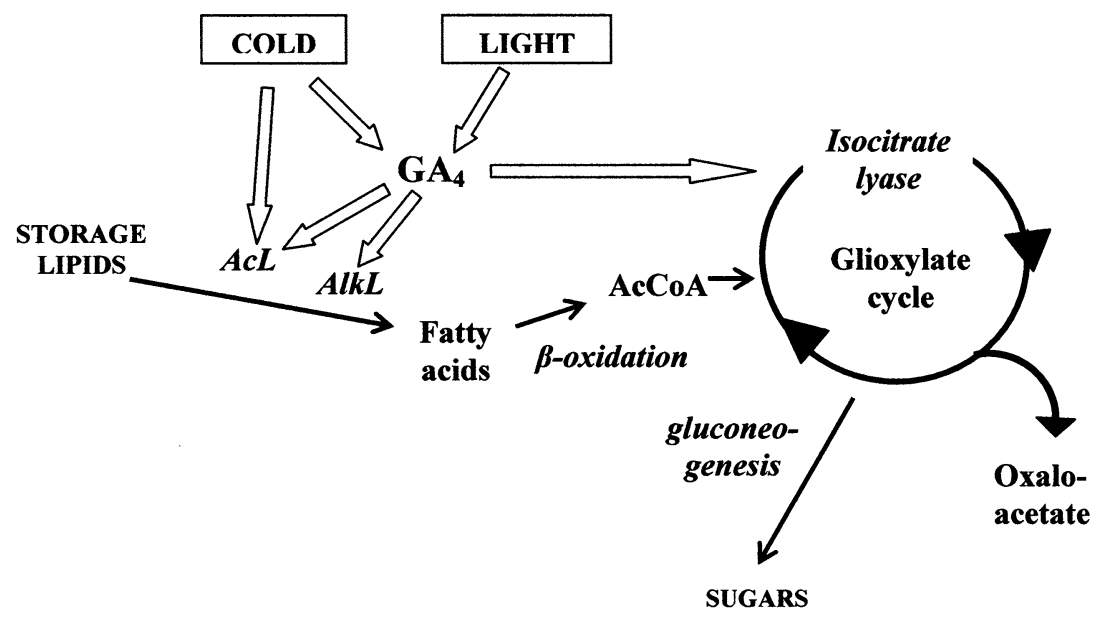




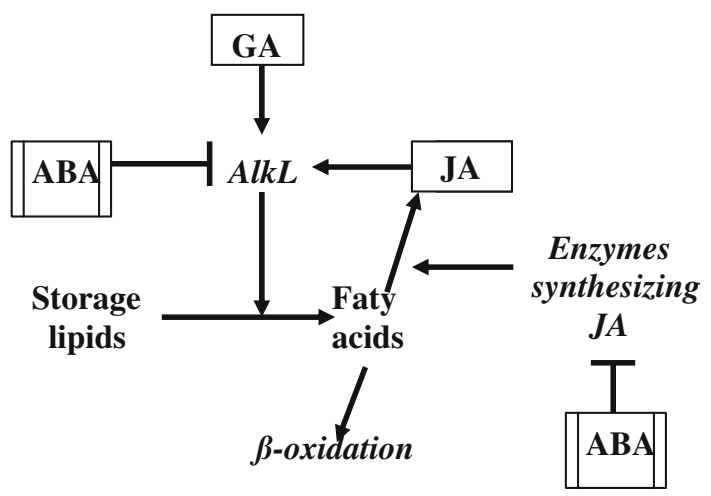

Fig. 6 Two possible sites of abscisic acid $(A B A)$ action on alkaline lipase (AlkL) activity in germinating dormant apple embryos. Mark -। on an arrow indicates inhibitory effect. $G A$ gibberellin, $J A$ jasmonic acid

triggered by light and GA. The scheme in Fig. 6 shows two possible positions of this second site of $\mathrm{ABA}$ action. One is a direct effect on AlkL activity; ABA would counteract the stimulatory action of JA and GA. Another possibility is the inhibition of JA synthesis by ABA that depends on the supply of linolenic acid, similarly as it has been recently demonstrated for another experimental model (Adie et al. 2007). The observation that the synthesis of JA is involved in the stimulation of germination and of AlkL activity supports the latter possibility. The scheme in Fig. 6 completes the relations shown in Fig. 5.

\section{Metabolism of carbohydrates}

Although sugars are not the main storage material of apple seeds (see "Carbohydrate metabolism"), they play important roles in the early metabolic events of germination as well as in removal of dormancy during stratification (Roberts 1969, Corbineau et al. 1989). Catabolism of carbohydrates is not only source of metabolic energy and of carbon skeletons for syntheses, but also monosaccharides are signaling molecules involved in several developmental processes in plants (Weber and Roitsch 2000; Koch 2004). As mentioned earlier ("Cyanides"), hydrogen cyanide strongly affects the catabolism of sugars in apple seeds during stratification through a selective control of the activity of several enzymes implicated in different catabolic pathways, and at the same time stimulates embryo germination and eliminates the secondary symptoms of embryonic dormancy (asymmetric growth and greening of cotyledons).

Cyanide that appears in a relatively high concentration during early seed stratification contributes to the supply of the embryo with monosaccharides; it markedly stimulates alkaline invertase (AlkI) (Bogatek et al. 1999). The activity of the enzyme is also controlled by jasmonate which inhibits AlkI in the upper (non-growing) cotyledons of cultured dormant embryos (Bogatek et al. 2002).

On the other hand, HCN inhibits the activity of glucose-6phosphate dehydrogenase, thus limiting the saccharideoriginated carbon flow through oxidative pentose phosphate path (PPP; Bogatek and Lewak 1988, 1991). At the same time HCN enhances the glycolytic sugar degradation by stimulating its key enzymes: pyruvate kinase and PPi-dependent phospho-fructokinase. This last activity is stimulated indirectly; HCN affects 2-kinase activity, thus contributing to the rise of fructose-2,6-bisphosphate level, which in turn stimulates phosphofructo-kinase (Bogatek 1995). These relations are schematically presented in Fig. 7.

\section{Protein metabolism}

As it has been mentioned earlier ("Protein metabolism"), the total protein level in apple embryos is only slightly affected by the low temperature of stratification, whereas the proteolytic activity rises markedly during the initial period of the treatment. This increase is due to some specific proteases; among them the enzyme hydrolyzing bonds adjacent to a cysteine residue is the best characterized (Żarska-Maciejewska and Lewak 1983). It is activated by low temperature, and its temperature optimum is $5^{\circ} \mathrm{C}$. On the other hand, there are no data on the effect of light on proteolytic activity.

Attempts to demonstrate effects of gibberellins or cytokinins on the activity of proteolytic enzymes have failed. In contrast, jasmonic and abscisic acids were effective when applied on isolated embryos in culture (Ranjan and Lewak 1995). JA stimulated all the activities tested, whereas ABA had generally an inhibitory action when a non-specific substrate (casein) was used. The picture was different when hydrolysis of native proteins of apple embryo by the crude enzyme extract was assayed: it was stimulated by both JA and ABA. It was then concluded that among different apple seed proteolytic activities toward native substrates there is one (or several) dominant stimulated also by ABA.

The ABA-induced secondary dormancy resulted in a blockage of cell cycle in the apple embryo axis in the G1 phase (Bouvier-Durand et al. 1989). Nuclear and nucleolar volumes were reduced, and their structure became similar to that seen in primary dormant embryos. This observation may indicate that in dormant embryos nucleic acids, and protein synthesis is inhibited by ABA.

\section{Secondary effects of dormancy}

By definition, the primary effect of dormancy is the inhibition, or slowing down, of growth ("Introduction" and "Environmental factors that affect dormancy in apple 
Fig. 7 Schematic presentation of sites of regulatory action of hydrogen cyanide and jasmonate $(J A)$ in the sugar catabolism in apple embryos. Mark $\bar{\eta}$ on an arrow indicates inhibitory effects

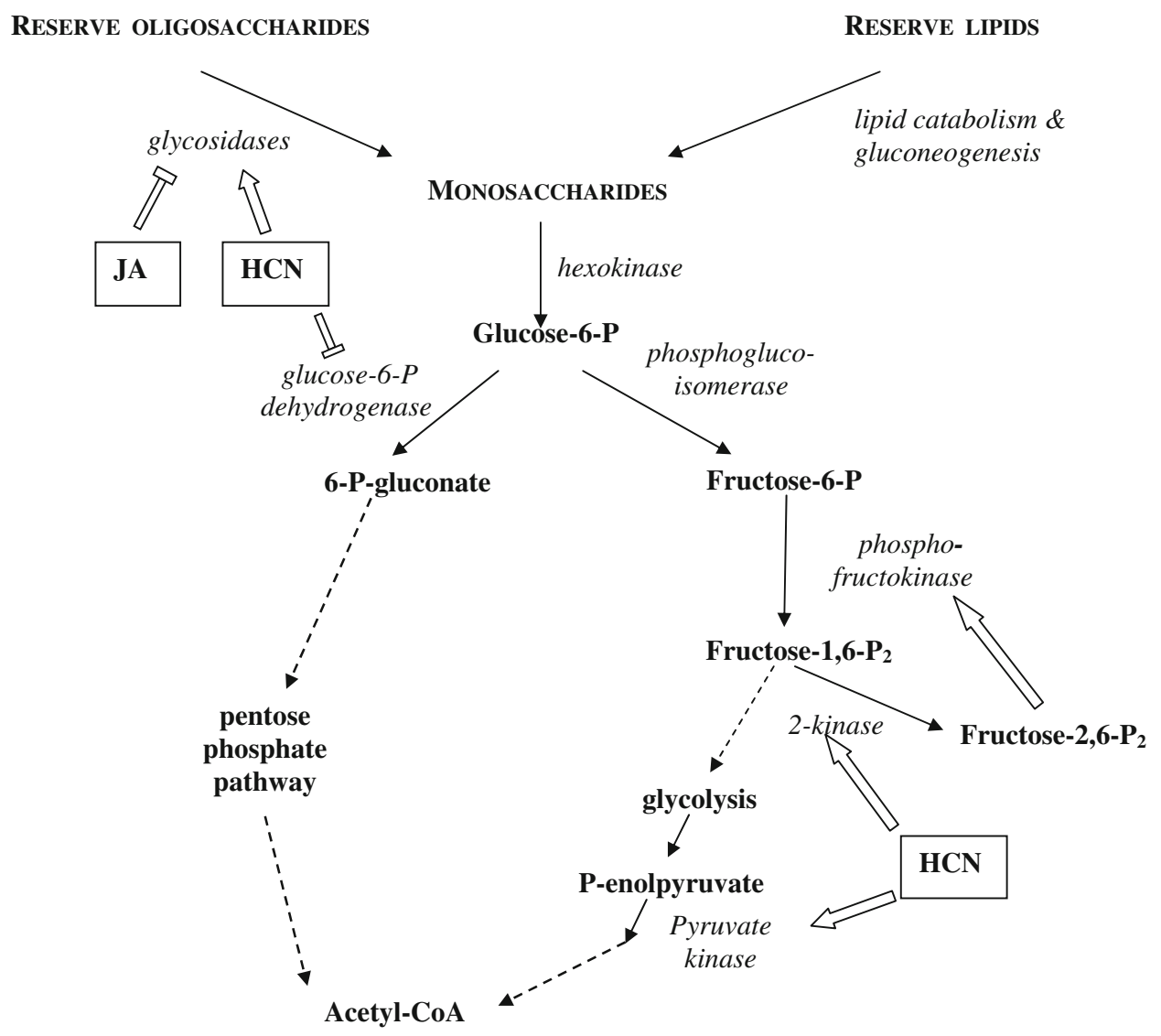

seeds"). The growth (germination) and development of seedlings from dormant isolated apple embryos and from such embryos in which dormancy is only partly removed (short stratification, treatment by light or gibberellin) are disturbed, and several morphological and physiological anomalies are observed in seedlings. The appearance of these features, differing from those of seedlings grown from non-dormant (stratified) embryos, can be considered as secondary, side, or post-effects of dormancy.

One of these effects of partly removed dormancy is the formation of seedlings with morphological anomalies, described in details by Côme $(1967,1970)$. Cotyledons of embryos isolated from dormant apple seeds grow asymmetrically; one cotyledon, usually the one being in better contact with humid medium of culture, increases considerably in size and, if illuminated, turns green, whereas the other one does not grow and remains white. Other anomalies concern mainly the development of the embryo radicle and hypocotyl.

\section{Growth asymmetry}

The growth asymmetry seems to be under hormonal control. It has been demonstrated that jasmonic acid inhibits the growth of cotyledons isolated from dormant embryos
(Bogatek et al. 2002). Its concentration in the lower cotyledon (one in contact with wet medium and growing faster) could be diminished as a result of simple diffusion, similarly as that of ABA ("Abscisic acid"), and thus, lead to growth asymmetry. Moreover, the asymmetry disappears in embryos treated with HCN ("Cyanides"). The intensity of storage sucrose hydrolysis is markedly higher in the upper cotyledon than in the lower one (Bogatek et al. 1999). In the upper (non-growing) cotyledon, JA was found to inhibit the activity of AlkI, the enzyme responsible for sucrose hydrolysis in cotyledons (Bogatek et al. 2002). In contrast, $\mathrm{HCN}$ treatment stimulated the activity. It can be, therefore, concluded that the growth asymmetry of cotyledons in dormant apple embryos in culture is under hormonal control, where the role of JA and HCN is evidenced, and that reserve sugar catabolism is implicated in this secondary effect of dormancy.

\section{Development of photosynthesis}

Another symptom (secondary effect) of embryonic dormancy, asymmetric greening of cotyledons, is obviously related to the development of photosynthetic activity. It was demonstrated that $\mathrm{CO}_{2}$ assimilation by germinating dormant apple embryos in culture starts ca. 10 days later 
than that of non-dormant (stratified) ones (Maciejewska et al. 1974). The rate of ${ }^{14} \mathrm{CO}_{2}$ incorporation into cultured embryos isolated from seeds after different periods of stratification was markedly lower in dormant embryos when compared with those stratified for longer than 20 days. The dormancy reduced also by ca. $50 \%$ the content of chlorophyll in cultured embryos.

The activity of enzymes involved in $\mathrm{CO}_{2}$ assimilation is markedly affected by dormancy. During the culture of non-dormant (stratified) apple embryos, the activity of ribulose bisphosphate carboxylase/oxygenase (RUBISCO) increased sharply reaching the maximum value after a week. The rise in RUBISCO activity in dormant embryos during the culture was delayed by 3 days, and its maximum value was only ca. $70 \%$ of that in non-dormant ones (Ryć and Lewak 1980). The activity of another carboxylating enzyme phosphoenolpyruvate carboxylase (PEPC) in embryos isolated from dormant seeds increased twofold during their culture, whereas in non-dormant embryos it decreased during the same time by one order of magnitude (Ryć and Lewak 1975). Activities of both glyceraldehyde phosphate dehydrogenases (NAD and NADP dependent) were ca. tenfold higher in non-dormant than in dormant embryos. The increase of NADP enzyme was sharper in dormant embryos in culture than in non-dormant ones. In contrast, the activity of NAD-dependent dehydrogenase rose considerably (by more than one order of magnitude) in cultured non-dormant embryos, but remained unchanged in dormant ones (Ryć and Lewak 1977).

As it could be expected, most features of photosynthetic apparatus are low in dormant embryos in culture and increase during dormancy removal. This was the case of the intensity of $\mathrm{CO}_{2}$ assimilation, chlorophyll content, as well as the activities of RUBISCO and glyceraldehyde dehydrogenases. The observation that the PEPC activity did not follow the same pattern since it was high in dormant embryos and low in stratified ones, led us to assume that different routes of $\mathrm{CO}_{2}$ assimilation are used in germinating dormant and nondormant embryos (Ryć and Lewak 1980). The dominant role of $\mathrm{CO}_{2}$ assimilation by PEPC in the early photosynthesis in apple seedlings was confirmed using a different experimental approach (Blanke and Ebert 1992).

The development of the photosynthetic activity in apple seedlings is under hormonal control. Chlorophyll accumulation in non-dormant embryos in culture was strongly inhibited by ABA treatment, similar to their germinability (Ryć and Lewak 1982). Although in dormant embryos application of GA or CK was without effect, treatment with a mixture of both hormones increased the chlorophyll content up to the level observed in non-dormant control embryos.

The RUBISCO activity in dormant embryos in culture was stimulated by GA, CK, and their mixture. In nondormant embryos, the enzyme was inhibited by $\mathrm{ABA}$ treatment down to the level observed in dormant ones. The effect was reversed by simultaneous GA treatment, but not by CK. The activity of PEPC in dormant embryos treated with a mixture of GA and CK was inhibited to the level found in non-dormant embryos; GA and CK applied separately had a weaker effect. The same enzyme activity was stimulated by ABA in non-dormant embryos, but the activity reached only half of that in dormant ones, and the stimulation was not reversed by simultaneous application of GA or CK. The incomplete reversibility of the ABA effects by GAs and CKs indicates that, although ABA is certain to participate in the onset and maintenance of embryonic dormancy, the mechanism involved in this phenomenon is more complicated than a simple hormonal balance. Moreover, the data discussed above do not confirm the Khan's hypothesis on selective roles of hormones in the control of dormancy, presented earlier ("Regulatory complex involved in dormancy removal").

\section{Persistence of dormancy in callus}

The persistence of some dormancy markers in subsequent generations of non-differentiated cells of calli derived from apple embryos of different depth of dormancy might also be considered as a post-effect of dormancy.

The growth rate, dedifferentiation ability, as well as the activity of some reserve-hydrolyzing enzymes ("Metabolic events occurring during dormancy removal") in apple calli were used as dormancy markers. The dedifferentiation of tissues of non-dormant (stratified) embryos was markedly faster than that of dormant ones (Sińska 1988). Moreover, embryo axes formed calli markedly more easily than did cotyledons. Also the frequency of morphological anomalies formation in regenerated plants (described above, "Growth asymmetry") depended on the depth of dormancy of tissues (axes and/or cotyledons) from which the calli had originated. The patterns of changes in the activities of alkaline invertase (AlkI), proteases hydrolyzing albumine, and cystine endopeptidase (hydrolyzing cystine-di- $\beta$ naphtylamide) in calli derived from axes and cotyledons of dormant seeds and seeds submitted to different periods of cold stratification followed almost exactly the pattern of these enzyme changes in intact axes and cotyledons isolated from the same seeds (Maciejewska and Lewak 2006).

The nature of the factor(s) responsible for persistent dormancy in apple embryo-derived calli remains unknown. The endogenous calli hormones certainly are not implicated in the control of dormancy-related (marker) enzyme activities although the activity of proteases in cultured apple embryos was shown to be inhibited by ABA (Ranjan and Lewak 1995); the subsequent generations of undifferentiated cells were supplied every 2 weeks, during the transfers into fresh medium, with relatively high concentrations of 
auxin and cytokinin, hormones that unquestionably are not involved in apple seed dormancy maintenance ("Auxins" and "Cytokinins").

\section{Conclusions, questions, and perspectives}

Dormancy in apple seeds, as defined in "Dormancy and processes cardinal for growth", is brought about by several barriers that inhibit processes cardinal for germination. Some of them are of a structural character; the seed coat hampers water access to the embryo, thus affecting the imbibition and as a result, hampers the function of many enzymes, membranes and cellular organelles. The same structure limits the entrance of oxygen to the embryo, affecting the oxidative processes. Other barriers are of developmental character; dormant embryo mitochondria need maturation before they reach full activity. The best studied are, however, the metabolic barriers that render successful germination impossible.

The blocks that hinder the metabolic processes in the embryo are affected (alleviated or eliminated) by environmental stimuli. In addition to water accessibility, the thermal conditions play here a primary role and, under specific circumstances, also light conditions. The effects of appropriate (low) temperature and light can be, to some extent, replaced by treatments with chemicals, mainly phytohormones. In addition to endogenous hormones ("Hormones and other regulators affecting apple embryonic dormancy"), also other elements of cellular signaling pathways are certain to operate. Sugar and lipid metabolism in apple seeds can be involved not only in reserve mobilization but also in the supply of signal molecules implicated in the control of the cardinal processes of dormancy removal, as it has been proposed recently for other experimental systems (e.g., Gibson 2005, Wang 2004). It seems to be of some interest that raffinose present in dormant apple seeds disappeared very early during stratification (Bogatek et al. 1999). It could be, therefore, concluded that this sugar is used as reserve material during dormancy removal despite that carbohydrates belonging the to raffinose family have been postulated to play a regulatory role in many seeds (e.g., Obendorf 1997).

The metabolic events leading to the removal of dormancy rely mostly on the mobilization of seed reserve materials in order to produce energy and intermediates for syntheses of cellular components indispensable for successful germination and subsequent growth and development of the seedling. Although the reserves are hydrolyzed and metabolized also after the completion of germination, the primary role of these processes in the pre-germinative events (dormancy removal) has been evidenced; not only the correlations between dormancy depth and activities of hydrolytic enzymes were demonstrated, but also the inhibition of these activities hampered germination of embryos, thus deepening their dormancy.

During the dormancy removal, a network of metabolic events and a complex of regulatory relations operate in apple embryo. Several elements of the network are described in the cited papers and discussed in this review. Others remain to be investigated. The recognized sites of action of the environmental and regulatory (chemical) factors are presented in Fig. 8.

The presented data (Hormones and other regulators affecting apple embryonic dormancy" and "Environmental and hormonal control of metabolic events") indicate a pivotal role of hormones and other regulatory molecules in the network. Some of them are activated and/or synthesized early during dormancy breaking (GAs, CKs, ethylene, JA, and $\mathrm{HCN}$ ), and others disappear at the same time (ABA). The changes in their levels have been shown to be induced by changing water relations (ABA and possibly ethylene), but also by low temperature treatment and light (GAs, CKs, $\mathrm{JA}$, and $\mathrm{HCN}$ ). They act pleiotropically, being involved in the control of different crucial enzyme activities that catalyze mobilization and transformations of reserves.

It is obvious that the concentration of a hormone in the cell is an important parameter that determines its effect, in parallel to the sensitivity of the responding (target) system. However, our knowledge about the mechanisms operating in apple seeds that determine the levels of particular hormones and participate in their observed changes is rather scarce. The inactivation of hormones by binding with sugars, amino acids, or short peptides has been evidenced, as well as the release of free active compounds from such conjugates. The enzymes implicated in these processes are, however, not jet identified, and the modes of their activation/inactivation by the factors affecting embryo dormancy remain mysterious. Similarly, the biosynthesis of some hormones (GAs and ethylene) has been shown to participate in the changes in their levels and to be induced by thermal and light conditions. Yet, the mode of the induction remains unknown.

There is some evidence that protein biosynthesis is involved in the observed changes in the activity of certain enzymes. It is tempting to assume the existence of some "dormancy genes" whose controlled expression would be responsible for the onset, maintenance, and removal of embryo dormancy. Obviously, their products would be involved in the induction and regulation of the processes cardinal for dormancy and germination. Genetic studies on Arabidopsis thaliana allowed the identification genes coding for some regulatory proteins. RGL2 was proposed to control germination by counteracting the events induced by endogenous seed gibberellin. $R G L 2$ gene is activated by seed imbibition; the high level of the RGL2 transcript in 
Fig. 8 Evidenced sites of action of cold (C), light (L), and growth regulators upon the metabolic barriers responsible for embryonic dormancy in apple seeds. AcL and AlkL acid and alkaline lipases,

respectively; $A B A$ abscisic acid; $G A$ gibberellin; $H C N$ hydrogen cyanide; $J A$ jasmonic acid

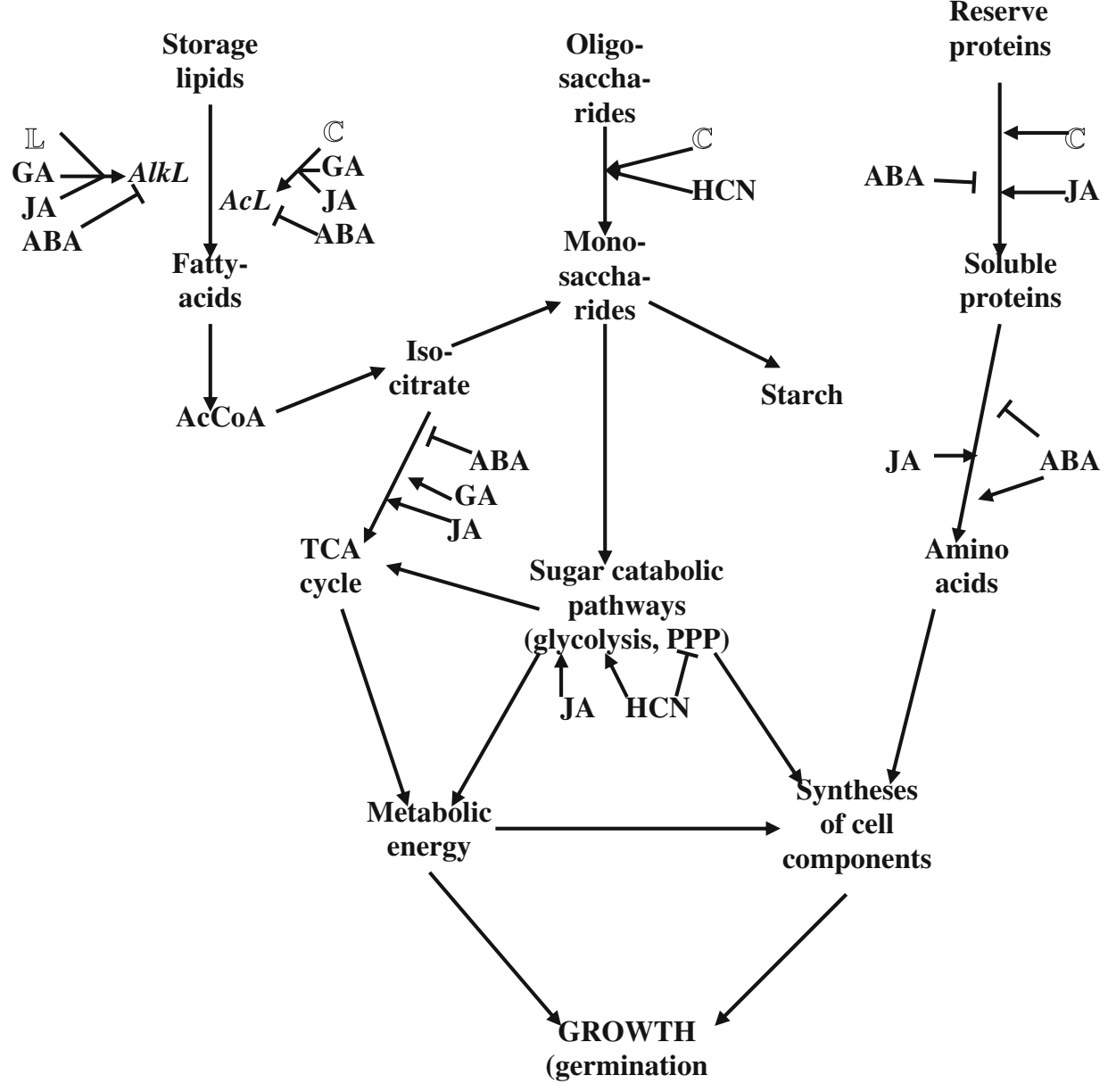

dormant seeds declines rapidly when germination begins (Lee et al. 2002; Peng and Harberd 2002). Unfortunately, this interesting hypothesis was not confirmed by subsequent studies (Bassel et al. 2004). On the other hand, a number of Arabidopsis genes implicated in gibberellin synthesis or metabolism have been identified; the coldinducible GA biosynthesis gene AtGA3ox is also positively regulated by light through phytochrome (Yamauchi et al. 2004), thereby integrating different signals that affect seed germination. Moreover, a light-regulated protein (PIL5) that controls GA responsiveness of germinating seeds was described recently (Oh et al. 2007). Another recently postulated mechanism of seed dormancy regulation relies upon chromatin remodeling; expression of the gene HUBI and/or $H U B 2$ was shown to be required for maintaining Arabidopsis seed dormancy (Liu et al. 2007). The HUB1 and HUB2 proteins are ligases responsible for monoubiquitination of histone $\mathrm{H} 2 \mathrm{~B}$, which is supposed to influence the transcription of several dormancy-related genes. No similar studies have been done on apple seed dormancy although a substantial part of the apple genome has already been sequenced, a bacterial artificial chromosome library constructed, and several linkage maps elaborated (e.g., Vinatzer et al. 1998; Liebhard et al. 2003; Beuning et al. 2005). Those studies were undertaken for the needs of breeders and/or phytopathologists and, according to my best knowledge, no functional analysis of individual genes has been performed. One can only hope that with the sophisticated genomic tools now in hand, the coming years will see their application to unraveling the biochemical and physiological phenomena collectively known as embryonic dormancy.

Open Access This article is distributed under the terms of the Creative Commons Attribution Noncommercial License which permits any noncommercial use, distribution, and reproduction in any medium, provided the original author(s) and source are credited.

\section{References}

Adie BAT, Péréz-Péréz J, Péréz-Péréz M-M, Godoy M, SánchezSerrano J-J, Schmetz EA, Solano R (2007) ABA is an essential signal for plant resistance to pathogens affecting JA biosynthesis and the activation of defenses in Arabidopsis. Plant Cell 19:1665-1681 
Avanzi S, Vernieri P, Ceccarelli N, Tagliasacchi AM, Forino LMC, Lorenzi R, Bonomo R (1988) Developmental stages and gibberellin activity in ovules of abscission-affected fruits of Malus domestica Borgh. J Plant Physiol 132:10-15

Balboa-Zavala O, Dennis FG (1977) Abscisic acid in apple seed dormancy. J Am Hortic Soc 102:633-637

Barthe P, Bulard C (1982) Influence of agar and sucrose on the behaviour of dormant apple embryos cultured in vitro. New Phytol 91:517-529

Barthe P, Bulard C (1983) Anaerobiosis and release from dormancy in apple embryos. Plant Physiol 72:1005-1010

Barthe P, Bulard C (1987) Absorption, distribution and leaching of [14C]ABA during culture of apple embryos. J Exp Bot 38:10021011

Bassel GW, Zielińska E, Mullen RT, Bewley JD (2004) Downregulation of DELLA genes is not essential for germination of tomato, soybean and Arabidopsis seeds. Plant Physiol 136:27822789

Beligni MV, Lamattina L (2000) Nitric oxide stimulates seed germination and de-etiolation, and inhibits hypocotyls elongation, three light-inducible responses in plants. Planta 210:215221

Beuning L, Bowen J, Persson H, Barraclough D, Bulley S, MacRae E (2005) Characterisation of MAl D1-related genes in Malus. Plant Mol Biol 55:369-388

Bewley JD (1997) Seed germination and dormancy. Plant Cell 9:1055-1066

Bewley JD, Black M (1982) Physiology and biochemistry of seeds, vol 2. Springer, Berlin

Bewley JD, Black M (1983) Physiology and biochemistry of seeds, vol 1. Springer, Berlin

Bianco J, Bulard C (1980) Changes in free and bound gibberellin levels in embryos of Pyrus malus cv. Golden Delicious during a chilling treatment applied to the seeds. Z Pflanzenphysiol 99:411-416

Blanke MM, Ebert G (1992) Phosphoenolpyruvate carboxylase and carbon economy of apple seedlings. J Exp Bot 43:965-968

Bogatek R (1995) The possible role of fructose 2,6-bisphosphate in the cyanide-mediated removal of embryonic dormancy in apple. Physiol Plant 94:460-464

Bogatek R, Gniazdowska A (2006) Nitric oxide and HCN reduce deep dormancy of apple seeds. Acta Physiol Plant 28:281-287

Bogatek R, Lewak S (1978) Respiratory processes during apple seed after-ripening. Acta Physiol Plant 1:45-51

Bogatek R, Lewak S (1988) Effect of cyanide and cold treatment on sugar catabolism in apple seeds during dormancy removal. Physiol Plant 173:406-411

Bogatek R, Lewak S (1991) Cyanide controls enzymes involved in lipid and sugar catabolism in dormant apple embryos during culture. Physiol Plant 183:422-426

Bogatek R, Rychter A (1984) Respiratory activity of apple seeds during dormancy removal and germination. Physiol Veg 22:181191

Bogatek R, Podstolski A, Ostaszewska A, Lewak S (1976) Phloridzin transformation and accumulation during the stratification of apple seeds and the culture of isolated embryos. Biol Plant 18:241-250

Bogatek R, Żarska-Maciejewska B, Sińska I, Lewak S (1989) The embryonic axis controls lipid catabolism in cotyledons of apple seeds during germination. Physiol Plant 176:557-562

Bogatek R, Dziewanowska K, Lewak S (1991) Hydrogen cyanide and embryonal dormancy in apple seeds. Physiol Plant 183:417-421

Bogatek R, Côme D, Corbineau F, Picard M-A, Żarska-Maciejewska B, Lewak S (1999) Sugar metabolism as related to the cyanidemediated elimination of dormancy in apple embryos. Plant Physiol Biochem 37:577-585
Bogatek R, Côme D, Corbineau F, Ranjan R, Lewak S (2002) Jasmonic acid affects dormancy and sugar catabolism in germinating apple embryos. Plant Physiol Biochem 40:167-173

Borkowska B, Rudnicki R (1975) Changes in the levels of cytokinins in apple seeds during stratification. Fruit Sci Rep 12:1-16

Bouvier-Durand M, Real M, Côme D (1989) Changes in nuclear activity upon secondary dormancy induction by abscisic acid in apple embryo. Plant Physiol Biochem 27:511-518

Bouyon C, Bulard C (1986) Heterogeneity of dormancy in apple embryos: a link with chlorophyll formation and content of abscisic acid. J Exp Bot 37:1643-1651

Bulard C (1985) Intervention by gibberellin and cytokinin in the release of apple embryos from dormancy: a reappraisal. New Phytol 101:241-249

Bulard C (1986) Conditions of induction of secondary dormancy in apple after breaking of primary dormancy by anaerobiosis and low temperature. Physiol Plant 67:279-284

Bulard C, Barthe P, Garello G, Le Page-Degivry MT (1974) Mise en evidenced'acide abscissique lie au $\beta$-D-glucopyranose dans les embryons dormants de Pyrus malus L. CR Acad Sci Paris 278:2145-2148

Côme D (1967) L'inhibition de la germination des graines de Pommier (Pirus malus L.) non dormantes. Rôle possible des phénols tégumentaires. Ann Sci Nat Bot 8:371-478

Côme D (1968) Relations entre l'oxygène et les phénomènes de dormance embryonnaire et d'inhibition tégumentaire. Bull Soc Frane Physiol Veg 14:3145

Côme D (1970) Les Obstacles à la Germination. Masson et Cie, Paris

Côme D (1980/81) Problems of embryonal dormancy as exemplified by apple embryo. Isr J Bot 29:145-156

Côme D, Perino C, Ralambosoa J (1985) Oxygen sensitivity of apple (Pyrus malus L.) embryos in relation to dormancy. Isr $\mathrm{J}$ Bot 34:17-23

Corbineau F, Carmignac DF, Gahan PH, Maple AJ (1989) Glycolytic activity in embryos of Pisum sativum and of non-dormant and dormant seeds of Avena sativa L. expressed through activities of PFK and PPi-PFK. Biochemistry 190:359-368

Daskalyuk AP (2002) Dormancy release, germination, and electrolyte leakage from apple embryos during stratification in the presence of sucrose. Russ J Plant Physiol 49:700-705

Daskalyuk AP, Toma OK, Yarotskaya LV, Nikita II (1996) Seed germination and polypeptide composition in early- and lateripening apple cultivars as related to stratification time. Russ J Plant Physiol 43:504-509

Dawidowicz-Grzegorzewska A (1989) Degradation of protein and lipid bodies during dormancy removal in apple seeds. J Plant Physiol 135:43-51

Dawidowicz-Grzegorzewska A, Lewak S (1978) Anatomy, histology and cytology of dormant and stratified apple embryos. I. General observations and changes in the starch content during afterripening of seeds. New Phytol 81:99-103

Dawidowicz-Grzegorzewska A, Żarska-Maciejewska B (1979) Anatomy, histology and cytology of dormant and stratified apple embryos. II. Storage protein degradation and correlated nucleoli development. New Phytol 83:385-393

Dawidowicz-Grzegorzewska A, Weisman N, Thévenot C, Côme D (1982) Proteolysis and dormancy release in apple embryos. Z Pflanzenphysiol 107:115-121

Dennis FG (1976) Gibberellin-like substances in apple seeds and fruit flesh. J Am Soc Hortic Sci 101:629-633

Dennis FG, Nitsch JP (1966) Identification of gibberellins $A_{4}$ and $A_{7}$ in immature apple seeds. Nature 211:781-782

Dennis FG, Martin GF, Gaskin P, MacMillan J (1980) Gibberellin in mature apple seeds-contaminants? Planta 147:375-377

Dong JG, Kim WT, Yip WK, Thonovan GA, Li L, Benne AB, Yang SF (1991) Cloning of cDNA encoding 1-aminocyclopropane-1- 
carboxylate synthase and expression of its mRNA in ripening apple fruit. Planta 185:38-54

Dong JG, Olson D, Silverstone A, Yang SF (1992) Sequences of a cDNA cloning for 1-aminocyclopropane-1-carboxylate oxidase homolog from apple fruit. Plant Physiol 98:1530-1531

Drewes FE, Van Staden J (1991) Reserve mobilisation during germination of Tagetes minuta L. Ann Bot 68:79-83

Durkee AB, Poapst PA (1965) Phenolic constituents in core tissues and ripe seed of McIntosh apples. J Agric Food Chem 13:137139

Dyer WE (1993) Dormancy associated embryonic mRNAs and proteins in imbibing Avena fatua caryopses. Physiol Plant 88:201-211

Dziewanowska K, Lewak S (1975) Indolylacetic acid oxidase in dormant apple embryos. Biol Plant 17:207-213

Dziewanowska K, Lewak S (1982) Hydrogen cyanide and cyanogenic compounds in seeds. V. Effects of cyanide and azide on germination of apple embryos in relation to their dormancy. Physiol Veg 120:171-177

Dziewanowska K, Lewak S (1987) Non-decarboxylating transformation of indol-3-acetic acid in apple seeds. Biol Plant 29:110-117

Dziewanowska K, Grochowska MJ, Lewak S (1974) Changes in phloridzin and chlorogenic acid content and in indolylacetic acid oxidase activity during development of apple seeds. Fruit Sci Rep 1:3-9

Dziewanowska K, Niedźwiedź I, Chodelska I, Lewak S (1979a) Hydrogen cyanide and cyanogenic compounds in seeds. I. Influence of hydrogen cyanide on germination of apple embryos. Physiol Veg 17:297-303

Dziewanowska K, Niedźwiedź I, Lewak S (1979b) Hydrogen cyanide and cyanogenic compounds in seeds. II. Changes in free $\mathrm{HCN}$ level in apple seeds during stratification. Physiol Veg 17:681-686

Dziewanowska K, Niedźwiedź I, Lewak S (1979c) Hydrogen cyanide and cyanogenic compounds in seeds. III. Degradation of cyanogenic glucosides during apple seed stratification. Physiol Veg 17:687-695

Eichholtz DA, Robitaille HA, Herrmann KM (1983) Protein changes during the stratification of Malus domestica Borkh. seed. Plant Physiol 72:750-753

Flemion F (1934) Dwarf seedlings from non-after-ripened embryos of peach, apple and hawthorn. Contr Boyce Thompson Inst 6:205209

Foley ME, Nichols MB, Myers SP (1993) Carbohydrate concentrations and interactions in afterripening-responsive dormant Avena fatua caryopses induced to germinate by gibberellic acid. Seed Sci Res 3:271-278

Fountain DF, Bewley JD (1973) Polisome formation and protein synthesis in imbibed but dormant lettuce seeds. Plant Physiol $52: 604-608$

Gay C, Corbineau F, Côme D (1991) Effects of temperature and oxygen on seed germination and seedling growth in sunflower (Helianthus annuus L.). Environ Exp Bot 31:193-200

Gibson SI (2005) Control of plant development and gene expression by sugar signalling. Curr Opin Plant Biol 8:93-102

Gniazdowska A, Dobrzyńska U, Babańczyk T, Bogatek R (2007) Breaking of the apple embryo dormancy by nitric oxide involves the stimulation of ethylene production. Planta 225:1051-1057

Halińska A, Lewak S (1978) The presence of bound gibberellins in apple seeds. Bulll Acad Pol Sci Ser Sci Biol 26:119-122

Halińska A, Lewak S (1987) Free and conjugated gibberellins in dormancy and germination of apple seeds. Physiol Plant 69:523530

Halińska A, Sińska I, Lewak S (1987) Embryonal dormancy in apple seeds is controlled by free and conjugated gibberellin levels in the embryonic axis and cotyledons. Physiol Plant 69:531-534
Han F, Ullrich SE, Clancy JA, Jittkov A, Romagosa I (1996) Verification of barley seed dormancy loci via linked molecular markers. Theor Appl Genet 92:87-91

Harrington GT, Hite BC (1923) After-ripening and germination of apple seeds. J Agric Res 23:153-161

Hsiao A, Vidaver W (1989) Effects of repetitive acid immersion, red light and gibberellin $\mathrm{A}_{3}$ treatments on phytochrome-mediated germination control of scoto dormant lettuce seeds. J Exp Bot 40:23-31

Isaia A, Bulard C (1978) Relative levels of some bound and free gibberellins in dormant and after-ripened embryos of Pyrus malus cv. Golden Delicious. Z Pflanzenphysiol 9:409-414

Jarvis BC, Frankland B, Cherry JH (1968) Increased nucleic acid synthesis in relation to the breaking of dormancy of hazel seed by gibberellic acid. Planta 8:257-260

Kamiński W, Pieniążek J (1968) The influence of growth regulators on the germination of the apple cultivar Antonówka seeds from which the seed coats were removed. Bull Acad Pol Sci 16:719_ 721

Kamiński W, Zagaja SW (1974) Secondary dormancy of apple seeds. Part I. Effect of higher temperatures (in Polish). Prace Inst Sad $18: 3-8$

Kawęcki Z (1970) Study of physiology of stratified apple seeds "Antonówka zwykła". II. Sugar content of stratified apple seeds (in Polish). Rocz Nauk Rolniczych A 96:7-21

Kefeli VI, Turetskaya RH, Pustovoitova TN, Saidova SA (1969) Effect of abscisic and paracoumaric acid on seed germination (in Russian). Dok Akad Nauk SSSR 186:1437-1440

Kępczyński J, Rudnicki RM (1976) Studies on ethylene in dormancy of seeds II. The effect of endogenous ethylene on afterripening of apple seeds in fruits stored at low temperature. Fruit Sci Rep 4:27-33

Kępczyński J, Rudnicki RM (1977) Studies on ethylene in dormancy of seeds. III. The effect of ethylene on some metabolic processes in apple embryos excised from seeds at various stages of afterripening. Fruit Sci Rep 4:38-43

Kępczyński J, Rudnicki RM, Khan AA (1977) Ethylene requirement for germination of partly after ripened Apple embryo. Physiol Plant 40:292-295

Khan AA (1975) Primary, preventive and permissive roles of hormones in plant systems. Bot Rev 41:391-420

Koch K (2004) Sucrose metabolism: regulatory mechanisms and pivotal roles in sugar sensing and plant development. Curr Opin Plant Biol 7:235-246

Kohorn BD (2000) Plasma membrane-cell wall contacts. Plant Physiol 124:31-38

Kopecky F, Sebanek J, Blazkova J (1975) Time course of the changes in the level of endogenous growth regulators during the stratification of the seeds of the "Panenske ceske" apple. Biol Plant 17:81-87

Korban SS, Bournival BL (1987) Catalase, esterase and peroxidase enzymes in seeds and leaves of Malus $\times$ domestica Borkh. Sci Hortic 32:213-219

Kozlowski TT, Pallardy SG (2002) Acclimation and adaptive responses of woody plants to environmental stresses. Bot Rev 68:270-334

Lang GA (1987) Dormancy: a new universal terminology. HortScience 122:817-824

Le Page-Degivry MT, Bulard C (1979) Acide abscisique lié et dormance embryonnaire chez Pyrus malus. Physiol Plant 46:115-120

Lee S, Cheng H, King KE, Wang W, He Y, Hussain A, Lo J, Harberd NP, Peng J (2002) Gibberellin regulates Arabidopsis seed germination via $R G L 2$, a $G A I / R G A$-like gene whose expression is up-regulated following imbibition. Genes Dev 16:646-658 
Lehmann E (1874) Über das amygdalin in den Fruchtkernen der Kirschen, Pflaumen, Pfirsiche und Äpfel, und über den Blausäure lieferden Bestandtheil der Faulbaumrinde und der Kirschbeerblätter. Pharm Z 13:43-46, 65-78

Letham DS, Williams MW (1969) Regulators of cell division in plant tissues. The cytokinins of the apple fruit. Physiol Plant 22:925-936

Lewak S (1980) Light, low temperature and hormone regulation of dormancy removal and seed germination, vol 29. Wissen Z E-MArndt-Uniwersität Greifswald, Math-Naturwiss Reihe, pp 3-5

Lewak S (1981) Regulatory pathways in removal of apple seed dormancy. Acta Hortic 120:149-159

Lewak S (1986) Peroxidases and germination. In: Greppin H, Penel C, Gaspar Th (eds) Molecular and physiological aspects of plant peroxidases. University of Geneva, Geneva, pp 367-374

Lewak S, Bryzek B (1974) The influence of cytokinins on apple embryo photosensitivity and acid phosphatase activity during stratification. Biol Plant 18:334-340

Lewak S, Smoleńska G (1968) Le système phytochrome dans la. germination des semences de Pommier. Physiol Veg 6:403-408

Lewak S, Białek K, Sińska I (1970) Sensitivity of apple seed germination to light and some growth regulators. Biol Plant 12:291-296

Lewak S, Rychter A, Żarska-Maciejewska B (1975) Metabolic aspects of embryonal dormancy in apple seeds. Physiol Veg 13:13-22

Liebhard R, Koller B, Gianfranceschi L, Gessler C (2003) Creating a saturated reference map for the apple (Malus $\times$ domestica Borgh.) genome. Theor Appl Genet 106:1497-1508

Liu Y, Koornneef M, Soppe WJJ (2007) The absence of histone H2B monoubiquitination in the Arabidopsis hubl (rdo4) mutant reveals a role for chromatin remodeling in seed dormancy. Plant Cell 19:433-444

Lu Y, Foo Y (1998) Constitution of some chemical components of apple seed. Food Chem 61:29-33

Luckwill LC (1957) Studies on fruit development in relation to plant hormones. IV. Acidic auxins and growth inhibitors in leaves and fruits of the apple. J Hortic Sci 32:18-33

Luckwill LC, Weaver P, MacMillan J (1969) Gibberellins and other growth hormones in apple seeds. J Hortic Sci 44:413-424

Maciejewska B, Lewak S (2006) Embryonic dormancy persists in the calli derived from apple embryo. Plant Cell Tissue Organ Cult 85:83-89

Maciejewska U, Ryć M, Maleszewski S, Lewak S (1974) Embryonal dormancy and the development of photosynthetic activity in apple seedlings. Physiol Veg 12:115-122

Milborrow BV, Vaughan G (1979) The long-term metabolism of ( \pm ) [2-14C] abscisic acid by apple seeds. J Exp Bot 30:983-995

Milborrow BV, Vaughan G (1982) Characterization of dihydrophaseic acid $4^{\prime}-O-\beta$-D-glucopyranoside as a major metabolite of abscisic acid. Aust J Plant Physiol 9:361-372

Mousdale MA, Knee M (1981) Indolyl-3-acetic acid and ethylene levels in ripening apple fruits. J Exp Bot 32:752-758

Neil SJ, Desikan R, Hancock JT (2003) Nitric oxide signalling in plants. New Phytol 159:11-35

Nguyen XV, Côme D (1984) Opposite effects of temperature on breaking of dormancy and on induction of frost resistance in apple embryos. Physiol Plant 62:79-82

Nguyen XV, Côme D, Lewak S, Mazliak P (1984) Dormancy breaking and frost resistance induction in apple embryos as related to changes in reserve and polar lipids. Physiol Plant 62:566-570

Nguyen XV, Côme D, Justin A-M, Lewak S, Mazliak P (1987) Quantitative changes in phosphatidylcholine molecular species and freezing avoidance of apple embryos. Plant Physiol Biochem 25:697-703
Nikolaeva MG (1967) Physiology of deep dormancy in seeds (in Russian). Leningrad, Nauka

Nikolaeva MG, Jankelevitch BB (1976) The influence of phytohormones on the growth and peroxidase activity of apple embryos. Fruit Sci Rep 3:1-4

Nitsch JP (1958) Presence de gibberellines dans l'albumen immature du pommier. Bull Soc Bot France 105:479-482

Obendorf RL (1997) Oligosaccharides and galactosyl cyclitols in seed desiccation tolerance. Seed Sci Res 7:63-74

Obrenovic S (1977) Contribution to the study of the incidence of endogenous cytokinins in apples during ripening (in Croatian). Arhiv za Poljoprivredne Nauke 112:139-146

Oh E, Yamaguchi S, Hu J, Yusuke J, Jung B, Paik I, Lee H-S, Sun T-P, Kamiya Y, Choi G (2007) PIL5, a phytochrome interacting bHLH protein, regulates gibberellin responsiveness by binding directly to the GAI and RGA promoters in Arabidopsis thaliana seeds. Plant Cell 19:1192-1208

Osborne DJ (1981) Dormancy as a survival stratagem. Ann Appl Biol 198:25-562

Osborne DJ, Dell'Aquila A, Elder RH (1984) DNA repair in plant cells. An essential event of early embryo germination in seeds. Folia Biol 30:155-169

Ozga J, Dennis FG (1989) Is ethylene required for apple seed or embryo germination? HortScience 24:331-333

Paillard N (1974) Influence des produits volatils émis par les pommes sur la germination des embryons de pommier. Physiol Veg 12:739-748

Pate JS (1975) Pea. In: Evans LT (ed) Crop physiology. University Press, Cambridge, pp 191-224

Peiser GD, Wang TT, Hoffman NE, Yang SF, Liu HW, Walsh CT (1984) Formation of cyanide from carbon 1 of 1-aminocyclopropane-1-carboxylic acid during its conversion to ethylene. Proc Natl Acad Sci USA 81:3059-3063

Peng J, Harberd N (2002) The role of GA-mediated signaling in the control of seed germination. Curr Opin Plant Biol 5:376-381

Perino C, Côme D (1981) Influence du cyanure de potassium sur la germination de l'embryon de pommier (Pyrus malus L.) non dormant. Physiol Veg 19:219-227

Perino C, Côme D (1991) Physiological and metabolical study of the germination phases in apple embryo. Seed Sci Technol 19:1-14

Pieniążek J, Grochowska MJ (1967) The role of the natural growth inhibitor (abscisin II) in apple seed germination and the changes in the content of phenolic substances during stratification. Acta Soc Bot Pol 36:579-587

Pinfield NJ, Dungey NO (1985) Seed dormancy in Acer: an assessment of the role of the structures covering the embryo. J Plant Physiol 120:65-81

Popov YUG (1967) Carbohydrate metabolism in apple tree seeds during post-harvest maturing (in Russian). Fiziol Rastenij 14:152-156

Ranjan R, Lewak S (1992) Jasmonic acid promotes germination and lipase activity in non-stratified apple embryos. Physiol Plant 86:335-339

Ranjan R, Lewak S (1994) Interaction of jasmonic acid with some plant growth regulators in the control of apple (Malus domestica) embryo germination. Plant Growth Regul 114:59-166

Ranjan R, Lewak S (1995) Interaction of jasmonic and abscisic acid in the control of lipases and proteases in germinating apple embryos. Physiol Plant 93:421-426

Ranjan R, Miersch O, Sembdner G, Lewak S (1994) Presence and role of jasmonate in apple embryos. Physiol Plant 90:548-552

Raymond P, Spiteri A, Dieuaide M, Gerhardt B, Pradet A (1992) Peroxisomal $\beta$-oxidation of fatty acids and citrate formation by a particulate fraction from early germinating sunflower seeds. Plant Physiol Biochem 30:153-161 
Roberts EH (1969) Seed dormancy and oxidation processes. Dormancy and survival. In: Symposia of Society of Experimental Biology. Cambridge University Press, Cambridge, vol 25, pp 161-192

Rudnicki R (1969) Studies on abscisic acid in apple seeds. Planta 86:63-68

Rudnicki R, Kamińska W, Pieniążek J (1971) The interaction of abscisic acid with growth stimulators in germination of partially after-ripened apple embryos. Biol Plant 13:122-127

Rudnicki R, Sińska I, Lewak S (1972) The influence of abscisic acid on the gibberellin content in apple seeds during stratification. Biol Plant 14:325-329

Ryan SN, McManus MT, Laing WA (2003) Identification and characterisation of proteinase inhibitors and their genes from seeds of apple (Malus domestica). J Biochem 134:31-42

Ryć M, Lewak S (1975) Activity of phosphoenolpyruvate carboxylase in apple seedlings in relation to embryonal dormancy. Photosynthetica 9:299-303

Ryć M, Lewak S (1977) Development of glyceraldehyde phosphate dehydrogenase activities in apple embryos in relation to their embryonal dormancy. Physiol Veg 15:355-362

Ryć M, Lewak S (1980) The role of abscisic acid (ABA) in regulation of some photosynthetic enzyme activities in apple seedlings in relation to embryonal dormancy. Z Pflanzenphysiol 96:195-202

Ryć M, Lewak S (1982) Hormone interactions in the formation of photosynthetic apparatus in dormant and stratified apple embryos. Z Pflanzenphysiol 107:15-24

Rychter A, Lewak S (1969) Polyacrylamide-gel electrophoresis of apple seed enzymes. Acta Biochim Pol 16:333-339

Rychter A, Lewak S (1971) Apple embryos peroxidases. Phytochemistry 10:2609-2613

Rychter A, Rudnicki R, Lewak S (1971) Regulation of acid phosphatase activity by abscisic acid and gibberellin in apple seeds during stratification. Bull Acad Pol Sci 19:211-214

Rychter A, Szkutnicka K, Lewak S (1972) Acid phosphatase and the low temperature requirement of apple seed stratification. Physiol Veg 10:671-676

Saniewski M, Czapski J, Nowacki J, Lange E (1987) The effect of methyl jasmonate on ethylene and 1-aminocyclopropane-1carboxylic acid production in apple fruits. Biol Plant 29:199-203

Seewaldt V, Priestley DA, Leopold AC, Feigensen GW, GoodsaidZalduondo F (1981) Membrane organization in soybean seeds during hydration. Planta 152:19-23

Siegień I, Bogatek R (2006) Cyanide action in plants-from toxic to regulatory. Acta Physiol Plant 28:483-497

Singh Z, Browning G (1991) The role of ABA in the control of apple seed dormancy re-appraised by combined gas chromatographymass spectrometry. J Exp Bot 42:269-273

Sińska I (1988) Callus formation and plant regeneration capacity of apple embryonic axes and cotyledons in relation to seed dormancy. Plant Sci 54:147-152

Sińska I (1989) Interaction of ethephon with cytokinin and gibberellin during the removal of apple seed dormancy and germination of embryos. Plant Sci 64:39-44

Sińska I, Gladon RJ (1984) Ethylene and removal of embryonal apple seed dormancy. HortScience 119:73-75

Sińska I, Lewak S (1970) Apple seed gibberellins. Physiol Veg 8:661-667

Sińska I, Lewak S (1977) Is the gibberellin $A_{4}$ biosynthesis involved in the removal of dormancy in apple seeds? Plant Sci Lett 19:163-170

Sińska I, Lewandowska U (1991) Polyamines and ethylene in the removal of embryonal dormancy in apple seeds. Physiol Plant 81:59-64
Sińska I, Lewak S, Gaskin P, MacMillan J (1973) Reinvestigation of apple-seed gibberellins. Planta 114:359-364

Smoleńska G, Lewak S (1971) Gibberellins and the photosensitivity of isolated embryos from non-stratified apple seeds. Planta 99:144-153

Smoleńska G, Lewak S (1974) The role of lipases in the germination of dormant apple embryos. Planta 116:361-370

Srivastava AK, Dey SC (1982) Physiology of seed dormancy in sunflower. Acta Agron Acad Sci Hung 31:70-80

Subbaiah T, Powell L (1987) Abscisic acid in dormant apple seed tissues-a rapid purification scheme using pre-packed columns and GCMS-SIM quantitation. Physiol Plant 71:203-206

Subbaiah TK, Powell LE (1992) Abscisic acid relationships in the chill-related dormancy mechanism in apple seeds. Plant Growth Regul 11:115-123

Takeno K, Taylor JS, Sriskandarajah S, Pharis RP, Mullins MG (1982) Endogenous gibberellin and cytokinin-like in cultured shoot tissues of apple, Malus pumila cv. Jonathan, in relation to adventitious root formation. Plant Growth Regul 1:261-268

Thévenot C (1980) Corrélations entre les cotyledons et l'axe de l'embryon de Pommier. Interprétatation de la dormance. Thesis, Université Paris VI

Thévenot C, Côme D (1971) Influence de la temperature et du mode d'imbibition sur la germination des embryons de Pommier (Pyrus malus L.) non dormants. C R Acad Sci Paris 273 D:25152527

Thévenot C, Gaspar T, Lewak S, Côme D (1977) Peroxidases in relation to removal of dormancy and germination of apple embryos. Physiol Plant 40:82-86

Thévenot C, Ralambosoa J, Simond-Cote E (1987) Influence of abscisic acid and oxygen supply on germination of more or less dormant apple embryos. Isr J Bot 36:101-112

Thomas TH (1992) Some reflections on the relationship between endogenous hormones and light-mediated seed dormancy. Plant Growth Regul 11:239-248

Tissaoui T, Côme D (1973) Levée de dormance de l'embryon de pommier (Pyrus malus L.) en absence d'oxygène et de froid. Planta 11:315-322

Vegis A (1964) Dormancy in higher plants. Annu Rev Plant Physiol $17: 185-224$

Villiers T (1972) Seed dormancy. In: Kozlowski TT (ed) Seed biology, vol 2. Academic Press, New York, pp 220-276

Vinatzer BA, Zhang H-B, Sansavini S (1998) Construction and characterization of a bacterial artificial chromosome library of apple. TAG Theor Appl Genet 97:1183-1190

von Raussendorf-Bargen G (1962) Indolderivate im Apfel. Planta $57: 471-482$

Wang X (2004) Lipid signalling. Curr Opin Plant Biol 7:329-336

Wang M, Heimovaara-Dijkstra S, Duijn B (1995) Modulation of germination of embryos isolated from dormant and nondormant barley grains by manipulation of endogenous abscisic acid. Planta 195:586-592

Weber H, Roitsch T (2000) Invertases and life beyond sucrose cleavage. Trends Plant Sci 5:47-48

Wierszyłłowski J (1960) Notes on the anatomical structure and chemical composition of the seeds of apple and pear (in Polish). Rocz Nauk Rolniczych A 81:205-228

Wills RBH, Scott KJ, Franklin MJ (1976) Abscisic acid and the development of storage breakdown in apples. Phytochemistry $15: 1817-1818$

Wyzińska D, Lewak S (1978) Morphological aspects of apple seedlings early development in relation to embryonal dormancy. Biol Plant 20:53-60

Yamauchi Y, Ogawa M, Kuwahara A, Kamiya Y, Yamaguchi S (2004) Activation of gibberellin biosynthesis and response 
pathways by low temperature during imbibition of Arabidopsis thaliana seeds. Plant Cell 16:367-378

Zagórski S, Lewak S (1980) Starch statolith involvement in growth and geotropic reaction in apple embryo axes. Plant Sci Lett 20:167-173

Żarska-Maciejewska B (1992) Lipolytic activity during dormancy removal in apple seeds. Plant Physiol Biochem 13:65-70

Żarska-Maciejewska B, Lewak S (1976) The role of lipases in the removal of dormancy in apple seeds. Planta 132:177-181
Żarska-Maciejewska B, Lewak S (1983) The role of proteolytic enzymes in the release from dormancy of apple seeds. Z Pflanzenphysiol 110:409-417

Żarska-Maciejewska B, Sińska I, Witkowska E, Lewak S (1980) Low temperature, gibberellin and acid lipase activity in removal of apple seed dormancy. Physiol Plant 148:532-535

Zhang YX, Lespinasse Y (1991) Removal of embryonic dormancy in apple (Malus $\times$ domestica Borkh) by 6-benzylaminopurine. Sci Hortic 46:215-223 